Article

\title{
Effects of Hygrothermal Ageing on the Interphase, Fatigue, and Mechanical Properties of Glass Fibre Reinforced Epoxy
}

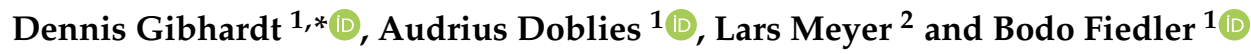 \\ 1 Institute of Polymer and Composites, Hamburg University of Technology, Denickestraße 15, 21073 Hamburg, \\ Germany; audrius.doblies@tuhh.de (A.D.); fiedler@tuhh.de (B.F.) \\ 2 Spitzner Engineers GmbH, Hein-Saß-Stieg 9, 21129 Hamburg, Germany; lars.meyer@spitzner-engineers.de \\ * Correspondence: dennis.gibhardt@tuhh.de; Tel.: +49-40-42878-8256
}

Received: 30 March 2019; Accepted: 6 June 2019; Published: 14 June 2019

check for updates

\begin{abstract}
Reliability and cost-effectiveness represent major challenges for the ongoing success of composites used in maritime applications. The development of large, load-bearing, and cyclically loaded structures, like rotor blades for wind or tidal energy turbines, requires consideration of environmental conditions in operation. In fact, the impact of moisture on composites cannot be neglected. As a result of difficult testing conditions, the knowledge concerning the influence of moisture on the fatigue life is limited. In this study, the impact of salt water on the fatigue behaviour of a glass fibre reinforced polymer (GFRP) has been investigated experimentally. To overcome the problem of invalid failure during fatigue testing, an improved specimen geometry has been developed. The results show a significant decrease in fatigue life for saturated GFRP specimens. In contrast, a water absorption of $50 \%$ of the maximum content showed no impact. This is especially remarkable because static material properties immediately decrease with the onset of moisture absorption. To identify the water absorption induced damage progress, light and scanning electron microscopy was used. As a result, the formation of debondings and cracks in the fibre-matrix interphase was detected in long-term conditioned specimens, although no mechanical loading was applied.
\end{abstract}

Keywords: composite; durability; environmental degradation; failure; debonding; moisture

\section{Introduction}

As the application of fibre reinforced polymers (FRPs) in structures subjected to challenging environmental conditions like humidity, moistness, salinity, or changing ambient temperatures has been increasing for years, there is a special interest in research on this topic. Limited knowledge of the material behaviour under demanding environmental conditions often leads to oversizing of components, and consequently restricts the full potential of composites. In particular, the development of current and future high-performance lightweight structures, for example, for rotor blades of wind energy or tidal turbines, is strongly dependent on the knowledge about the short- and long-term material reliability. However, in other areas, such as the offshore and marine industries or when pipelines are used, the long-term properties of the composite materials can be important when exposed to water or extreme humidity. A large number of application areas also means that knowledge about different material properties is important.

In this active research topic, many questions remain unanswered, although a large number of studies have already been carried out. Most authors have stated that moisture absorption has negative influences on the mechanical properties of various FRPs [1-8]. The obtained results suggest that a couple of complex mechanisms act on the three constituents of the composite, namely, the 
fibre, the matrix, and the fibre-matrix interphase. Physical and chemical ageing, such as matrix plasticization, hydrolysis effects, additional stresses due to swelling, interphase debonding, crack formation, and stress corrosion phenomena, appear as a result of moisture diffusion into the composite. However, the study of ageing under harsh environmental conditions is often difficult. Tests are usually very time-consuming and thus expensive. In addition, numerous different test procedures are required by offshore standards for an exact and reliable description of the material behaviour $[9,10]$. Researchers have presented many studies based on different ageing and testing conditions. The scope of the investigations ranges from studies lasting up to 10 years under outdoor conditions $[4,11,12]$ to short-term experiments at almost boiling water conditions $[13,14]$. However, accelerated tests are most commonly used below the polymer glass transition temperature $\left(\mathrm{T}_{\mathrm{g}}\right)$ at a range between $30^{\circ} \mathrm{C}$ and $70{ }^{\circ} \mathrm{C}[1,2,5,7]$. Problematically, because of the relatively low number of results published so far, transferability to other environmental conditions or material combinations is often not possible, even if some general trends can be derived from these investigations. In the future, it will be necessary to identify and understand the mechanisms of damage that occur in order to develop reliable and faster test procedures for long-term performance. A further step, therefore, is to investigate the changes in the mechanical properties of a glass FRP (GFRP) under different static and cyclic load conditions and at variable moisture contents, as done within the present study.

The interaction of diffusion properties and mechanical properties of composites also appears to be of particular interest. Although diffusion in composites is more complex than in homogeneous materials, numerous authors report that water uptake characteristics are often well described by the principle of Fickian diffusion $[15,16]$. Others, in contrast, have reported strong deviations from Fick's laws, especially in long-term experiments and at elevated temperatures [17]. So far, there are a few studies that investigate the diffusion properties at different temperatures or carry out mechanical tests after variable conditioning periods, but there is often no link between the two types of tests [17-19]. A full picture of dependencies is still missing.

As a first step, most authors focus on the determination of the macroscopic effect of humidity on the static properties of the material as they are essential for most applications. In contrast, environmental fatigue experiments are rarely realised so far because they are time-consuming and elaborate to perform $[2,18,20]$. For unidirectional glass fibre reinforced epoxy composites, it is evident that tensile strength is one of the main affected characteristics, with a large variance in presented results. Whereas some authors refer to a decrease in strength of about $5 \%-15 \%[7,21]$, others found drastic reductions of up to $50 \%$ [22]. Previous studies dealing with the tensile fatigue performance of unidirectional GFRP laminates under the influence of moisture have produced partly contradictory results. For example, the results of Mandell et al. [2,23] are different from those of Guzman and Brøndsted [4] related to the OPTIMAT BLADES project. While the former describe in particular a significant shortening of the fatigue life at high loads, the latter could hardly detect any differences, although the specimens were immersed in salt water at room temperature for up to eight years. Nevertheless, a comparison of previous studies is difficult. For the above-mentioned studies, for example, some differences have to be considered. In addition to the exact fibre-matrix combination, the investigations also differ in the geometry of the specimens and the water temperature. As long as, for example, the extent of the influence of elevated conditioning temperatures on the results is not known, it is difficult to describe generally valid relationships across studies.

Studies on multidirectional laminates according to Davies et al. [6] and Jaksic et al. [24] indicate that the effect of moisture on the fatigue life of GFRP laminates is also dependent on the lay-up and, therefore, on the dominant failure mechanisms. For laminates that include a high proportion of off-axis fibres, the humid aged fatigue performance is reduced at every load level and up to almost two orders of magnitude [6,24]. As the strength limiting matrix and interphase often suffer more from humid ageing than the fibres, a laminate lay-up defined by off-axis fibres leads to severe degradation of fatigue life. The results from Rocha et al. [1] and Gagani et al. [5], which have shown drastic reductions in 
fatigue performance during the investigation of shear strength, also confirm this hypothesis. In all cases, only fully saturated test specimens have been considered so far.

One aim of this work is, therefore, to contribute to the understanding of the ageing behaviour of GFRPs under moisture exposure by combining different static and cyclic tests, as well as analysing their failure mechanisms. Tensile-compression fatigue tests were carried out under different contents of absorbed water, as there are no published results for this application-relevant case by now. Remarkably, these tests show that the fatigue life is only affected by a water content of more than half of the saturation value, although the static strength is already noticeably reduced at this point. In order to address the problem of grip failure and its possible negative influence on fatigue life, a double-sided milled specimen geometry was selected on the basis of a detailed preliminary investigation. Additionally, absorption tests at different temperatures, tensile static, bending, and interlaminar shear tests at different water contents were performed to characterise the investigated material in more detail. On the basis of the findings of the present work, needs and subjects for prospective research are discussed.

\section{Materials and Methods}

\subsection{Materials and Composite Specimen Preparation}

GFRP laminates were manufactured using the resin transfer moulding (RTM) process. Silane coated E-glass fibre fabrics with an areal weight of $600 \mathrm{~g} / \mathrm{m}^{2}\left(528 \mathrm{~g} / \mathrm{m}^{2}\right.$ in $0^{\circ}$ direction and $54 \mathrm{~g} / \mathrm{m}^{2}$ in $90^{\circ}$ direction), provided by R\&G Faserverbundwerkstoffe, Waldenbuch, Germany, were applied for the preparation of 4-ply ( $2 \mathrm{~mm}$ thick) and 8-ply ( $4 \mathrm{~mm}$ thick) laminates. All fabrics were orientated in the $0^{\circ}$ direction. For the infusion, a two-component epoxy resin system consisting of Hexion EPIKOTETM Resin MGSTM RIMR 135 and the amine hardener EPIKURE ${ }^{\text {TM }}$ Curing Agent MGS' ${ }^{\text {TM }}$ RIMH 137 was mixed with a mass ratio of 100:30. The resin infusion was forced by a pressure difference between vacuum on the trap side and ambient pressure on the source side. Curing was performed at $30^{\circ} \mathrm{C}$ for $24 \mathrm{~h}$, under a pressure of $2 \mathrm{bar}$. Post-curing was then performed at an ambient pressure at $80^{\circ} \mathrm{C}$ for $16 \mathrm{~h}$.

The specimens preparation consisted of cutting, milling, and polishing before the drying and conditioning procedures started. During milling, a spherical ball end mill and a high number of feeds were used to assure smooth surfaces and avoid damaging the specimens. After polishing the edges with sandpaper of a grit size of 1000, all dimensions of each machined sample were measured to ensure comparability and high quality. The laminate qualities were checked by $\mathrm{T}_{\mathrm{g}}$ measurements, using a differential scanning calorimetry (DSC) system (Netzsch DSC 204 F1, Selb, Germany) and by visual inspection of polished micrographs. The study incorporates a total of 13 laminates. Table 1 lists the results of the quality control.

Table 1. Laminate and specimen properties including the standard deviations (SD). In the case of the fatigue samples, the thickness and width are measured at the machined gauge section.

\begin{tabular}{ccccc}
\hline $\begin{array}{c}\text { Type of Specimen } \\
\text { (Number of Laminates) }\end{array}$ & $\mathbf{T}_{\mathbf{g}}$ in ${ }^{\circ} \mathbf{C}$ (SD) & $\begin{array}{c}\text { Thickness in } \\
\mathbf{m m} \text { (SD) }\end{array}$ & $\begin{array}{c}\text { Width in } \mathbf{~ m m} \\
\text { (SD) }\end{array}$ & $\begin{array}{c}\text { Fibre Volume } \\
\text { Fraction in \% (SD) }\end{array}$ \\
\hline 4-ply laminates (2) & $87(1.0)$ & $/$ & $/$ & $44.1(0.5)$ \\
8-ply laminates (11) & $87(1.0)$ & $/$ & $/$ & $44.4(0.4)$ \\
Tensile tests & $/$ & $2.04(0.01)$ & $24.95(0.13)$ & $/$ \\
Fatigue tests & $/$ & $2.05(0.10)$ & $17.98(0.17)$ & $/$ \\
Bending tests & $/$ & $4.01(0.02)$ & $14.91(0.17)$ & $/$ \\
ILSS tests & $/$ & $4.01(0.03)$ & $8.14(0.15)$ & $/$ \\
\hline
\end{tabular}

\subsection{Experimental Methods and Fatigue Specimen Design}

With the aim to examine the effects of moisture absorption in GFRP under varying mechanical load cases, an experimental testing schedule was designed, which consisted of standard static tensile, bending, and shear tests, as well as a tension-compression fatigue investigation. Here, the latter 
certainly is the most essential, as almost no comparable studies exist to date, although, for example, increasing dimensions of wind energy and tidal turbine blades cause alternating loads to their composite components.

Potentially, this scarcity of published results is the result of technical difficulties with the failure behaviour of composites, containing a high share of fibres in the load direction when tension or even alternating loads are acting. The issue with this type of fatigue test is often a failure inside or near the gripping region, which is assumed to underestimate the lifetime as a result of the complex stresses acting, the load introduction to the test specimen, and a perceptible temperature increase [25-27]. In order to generate meaningful fatigue results, elaborate preliminary investigations concerning the tab area and the specimen geometry were performed and analysed. In fact, it became apparent that using a standard rectangular geometry, different tab materials and adhesives consistently led to unacceptable failure and damage inside the gripping region. More to the point, the tests with four different adhesives (epoxy and cyanate esters) and four different tab configurations (aluminium and GFRP variation) did not result in a significant improvement. Furthermore, thermography measurements indicated improper local heating of up to $50{ }^{\circ} \mathrm{C}$ inside the gripping region within the first 2000 cycles. This caused temperature differences of more than $20^{\circ} \mathrm{C}$ in comparison with the free length of the specimen, which was defined as unacceptable. Consequently, as a next step, the specimen geometries (thickness, width, or both) were modified, in order to shift the area of highest stresses towards the free specimen length. An additional set of tests was performed without tabs, to avoid friction due to adhesive failures of the bonded tabs and to allow good heat dissipation. However, a shift of the failure location towards the free length was not accomplished without machining both the thickness and the width of the specimen. The corresponding results are illustrated in Figure 1 and demonstrate a fatigue life increase of up to a factor of ten. For particularly long lifetimes, it has to be considered restrictively that the damage occurring in the free length can also grow in the direction of the grips, as shown in image of image of typical failure modes of fatigue specimens. As the previously described influence of the specimen geometry on fatigue life can be comparatively large, disregarding the common problem of invalid failure modes might mask other effects like the ones induced by moisture.

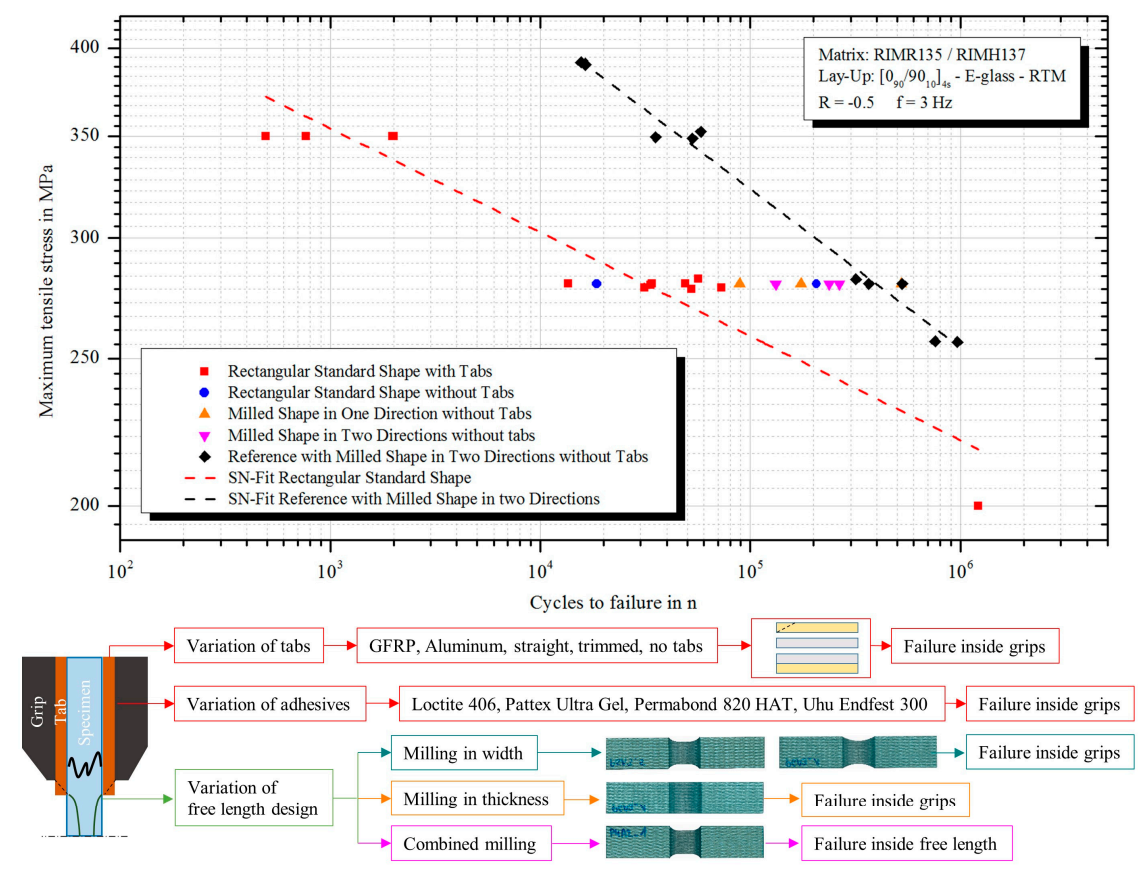

Figure 1. Results of the fatigue lifetime investigations concerning the tab area and the free specimen length. Invalid failure inside the grips occurred for all samples without a modified design. An overview of the tested variations is given in the lower part. GFRP-glass fibre reinforced polymer. 
For the specimen design, a short free length was favourable in order to avoid the use of an anti-buckling device, which might introduce additional friction forces and heating. Consequently, the gradual reduction of the thickness and width led to stress concentrations within the free length, which could not be entirely eliminated. The dimensions of these stress concentrations were analysed with a finite element analysis, which indicated a stress concentration factor (SCF) of about 1.3 in comparison with the nominal stress, as shown in Figure 2. Although it is known that dogbone-shaped geometries represent often inhomogeneous stress distributions, a need for alternatives to the straight specimens mentioned in standards like DIN EN ISO 527 or ASTM D3039 is given. For the chosen design, a radius was introduced to the thickness of the sample. The width was reduced in the central section and a radius was introduced here as well. Fraisse and Brøndsted [28] recently developed a similar geometry for compression fatigue tests. Supplementary measurements of the temperature distribution for the new type of test specimen confirmed a homogeneous temperature distribution with an average temperature of $32{ }^{\circ} \mathrm{C}$.

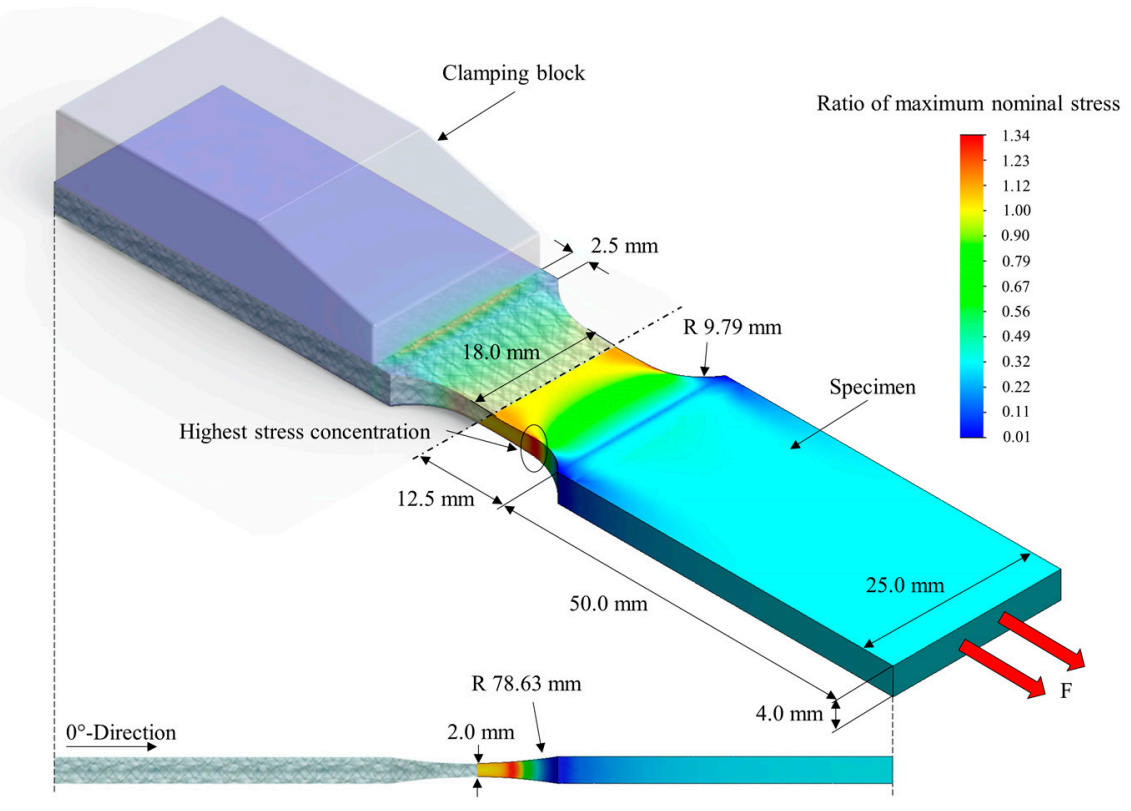

Figure 2. Fatigue specimen design and exemplary tensile stress concentration factor (SCF) distribution during testing.

Fatigue tests were performed in air under dry, saturated, and half-saturated conditions subsequent to immersion in $50^{\circ} \mathrm{C}$ artificial seawater according to DIN 50905. In the case of the aged specimens, a polymer box containing wet fleece was placed around the free gauge length to avoid fast re-drying during testing. Consistently, all tests were realised on an Instron servohydraulic testing machine with a maximum axial load capacity of $100 \mathrm{kN}$ in tension and compression. Load-controlled tests were carried out with a frequency of $3 \mathrm{~Hz}$ and an R-value of -0.5 , to reduce the influence of the compression loading to the damage progress.

\subsection{Water Absorption Studies}

The diffusion characteristics of FRPs are dependent on many parameters like the exact constituents of fibre and matrix, as well as of their fibre volume fraction and fibre orientations. Besides, production process specific properties such as density, porosity, and number of defects also have a considerable influence. Furthermore, physical and chemical aspects such as the crosslinking or defect density and distribution, as well as the polymer chain polarity, have a strong influence on the diffusion rate and total water uptake [29-31]. 
The absorption behaviour of the considered composite was investigated by immersion in artificial seawater according to DIN 50905 [32]. Before immersion in the water bath, all specimens were dried in an oven at $50{ }^{\circ} \mathrm{C}$ and a pressure of five mbar for $96 \mathrm{~h}$. The specimen weight change $M_{t}$ was calculated as follows:

$$
M_{t}=\frac{m_{t}-m_{0}}{m_{0}} \times 100,
$$

where $m_{t}$ is the current mass after immersion time $t$ and $m_{0}$ is the specimen mass after initial drying. Additionally, calculations of the theoretical water absorption according to Fick's laws were based on the fundamental works of Crank et al. [33] and Shen et al. [34]. The weight change for an idealised one-dimensional water diffusion through the surfaces (not considering the edges) of the composite thus is given by the following:

$$
M_{t}=M_{\infty}\left\{1-\frac{8}{\pi^{2}} \sum_{n=0}^{\infty}\left[\frac{1}{(2 n+1)^{2}} \exp \left(-\frac{D_{c} \pi^{2}(2 n+1)^{2} t}{h^{2}}\right)\right]\right\}
$$

where $M_{\infty}$ is the uptake at saturation, $D_{c}$ the diffusion coefficient of the composite calculated by absorption experiments, $h$ the specimen thickness, and $n$ the summation index.

Mechanical tests were performed at different amounts of absorbed water. On the basis of the expectation that the average quantity of water inside composite parts of offshore structures will be mainly between $0.3 \mathrm{wt} . \%$ and $0.8 \mathrm{wt} . \%$ (depending on the fibre volume fraction and environment) over time $[12,18]$, the four testing levels described in Table 2 were selected. Even if the moisture distribution is uneven in intermediate states, this is a situation as it always exists in real structures. Specimens used for the fatigue investigation were machined before immersion.

Table 2. Experimental testing scheme, specimen dimensions, and number of tested samples (brackets).

\begin{tabular}{|c|c|c|c|c|c|c|c|}
\hline $\begin{array}{l}\text { Investigation/ } \\
\text { Dimensions }\end{array}$ & Standard & Dry & $\begin{array}{l}\text { SW50 }{ }^{\circ} \mathrm{C} \\
0.3 \text { wt. } \%\end{array}$ & $\begin{array}{l}\mathrm{SW} 50{ }^{\circ} \mathrm{C} \\
0.6 \text { wt. } \%\end{array}$ & $\begin{array}{l}\mathrm{SW} 50^{\circ} \mathrm{C} \\
\text { Saturation }\end{array}$ & $\begin{array}{l}\text { SW50 }{ }^{\circ} \mathrm{C} \\
\text { Re-Dried }\end{array}$ & $\begin{array}{l}\mathrm{SW} 22{ }^{\circ} \mathrm{C} \\
0.3 \text { wt. } \%\end{array}$ \\
\hline $\begin{array}{c}\text { Static tensile } \\
250 \times 25 \times 2 \mathrm{~mm}^{3}\end{array}$ & $\begin{array}{l}\text { DIN EN } \\
\text { ISO 527-4 }\end{array}$ & (5) & (5) & (5) & (5) & (2) & (5) \\
\hline $\begin{array}{c}\text { Static } 4 \mathrm{pb} \\
120 \times 15 \times 4 \mathrm{~mm}^{3}\end{array}$ & $\begin{array}{l}\text { DIN EN } \\
\text { ISO } 14125\end{array}$ & (5) & (5) & (5) & (5) & l & l \\
\hline $\begin{array}{c}\text { ILSS } \\
24 \times 8 \times 4 \mathrm{~mm}^{3}\end{array}$ & $\begin{array}{l}\text { ASTM } \\
\text { D2344 }\end{array}$ & (5) & (5) & (5) & (5) & l & l \\
\hline T-C-Fatigue & l & $(12)$ & / & (11) & (13) & / & l \\
\hline Fracture Analysis & / & $x$ & $x$ & $x$ & $x$ & $x$ & $x$ \\
\hline
\end{tabular}
Fracture analysis was performed for all configurations $(x)$.

\subsection{Static Mechanical Testing}

The static tests were executed on a $400 \mathrm{kN}$ universal testing machine (ZwickRoell GmbH \& Co. KG, Ulm, Germany) in the case of the tension tests (DIN EN ISO 527) and on a $10 \mathrm{kN}$ universal testing machine (ZwickRoell GmbH \& Co. KG, Ulm, Germany) for the flexural tests. Loading was applied with a constant displacement speed of $1 \mathrm{~mm} / \mathrm{min}$ until the final failure occurred. Four point bending flexural tests (DIN EN ISO 14125) were set up with distances between the rollers of $30 \mathrm{~mm}$ at the upper side and $90 \mathrm{~mm}$ at the lower side. The failure mode in the case of the dry reference samples was constantly initiated by a compressive failure underneath the upper rollers. Therefore, preliminary tests with different support roller diameters have been executed. Finally, the upper diameter was set to $12 \mathrm{~mm}$ and the lower to $8 \mathrm{~mm}$, as the failure of the aged samples was only slightly affected by compression beneath the rollers. In summary, it cannot be excluded that the flexural strength of the reference could not be higher. Nevertheless, failure under compression is reasonable, as typically, the compressive strength of GFRP is slightly lower than the tensile strength. The deformation was recorded 
using an inductive displacement transducer by means of the outer fibre strain. For interlaminar shear strength (ILSS) tests (ASTM D2344), the support roller distance was set to $16 \mathrm{~mm}$ and the diameter of the rollers was $6 \mathrm{~mm}$ for the upper and $4 \mathrm{~mm}$ in the case of the lower. Schematic illustrations are given in Appendix A (Figure A1).

\section{Results and Discussion}

\subsection{Diffusion Behaviour}

Within the present study, water absorption in terms of mass gain and maximum water content was recorded for three environmental conditions. As can be seen in Figure 3, it became apparent that water absorption, both at room temperature and at $50{ }^{\circ} \mathrm{C}$, can be described sufficiently well with Fick's laws. Up to the time measured, no deviations in mass gain of more than four percent could be detected between the experiments and the theoretical values according to (2). The measured or expected saturation values also appear reasonable. Authors such as Rocha et al. [1,16] have published comparable results with detailed diffusion studies for comparable materials. With immersion in $50{ }^{\circ} \mathrm{C}$ salt water, a saturation of $1.07 \%$ mass gain was almost reached after 18 weeks. Saturation after immersion in salt water at room temperature was not reached until 18 months, in contrast. However, under ideal diffusion according to (2), it is assumed that a maximum weight increase of about $0.90 \%$ will be reached after two years. Additionally, the moisture absorption under variable laboratory conditions $\left(22{ }^{\circ} \mathrm{C}\right.$ and $25 \%-75 \%$ relative humidity (RH)) was monitored. The varying increase and decrease in weight is a consequence of the changing humidity in the laboratory with the seasons. Within this period, a maximum weight increase of $0.27 \%$ was recorded. This allows a rough estimation of the humidity absorption under ambient indoor conditions.

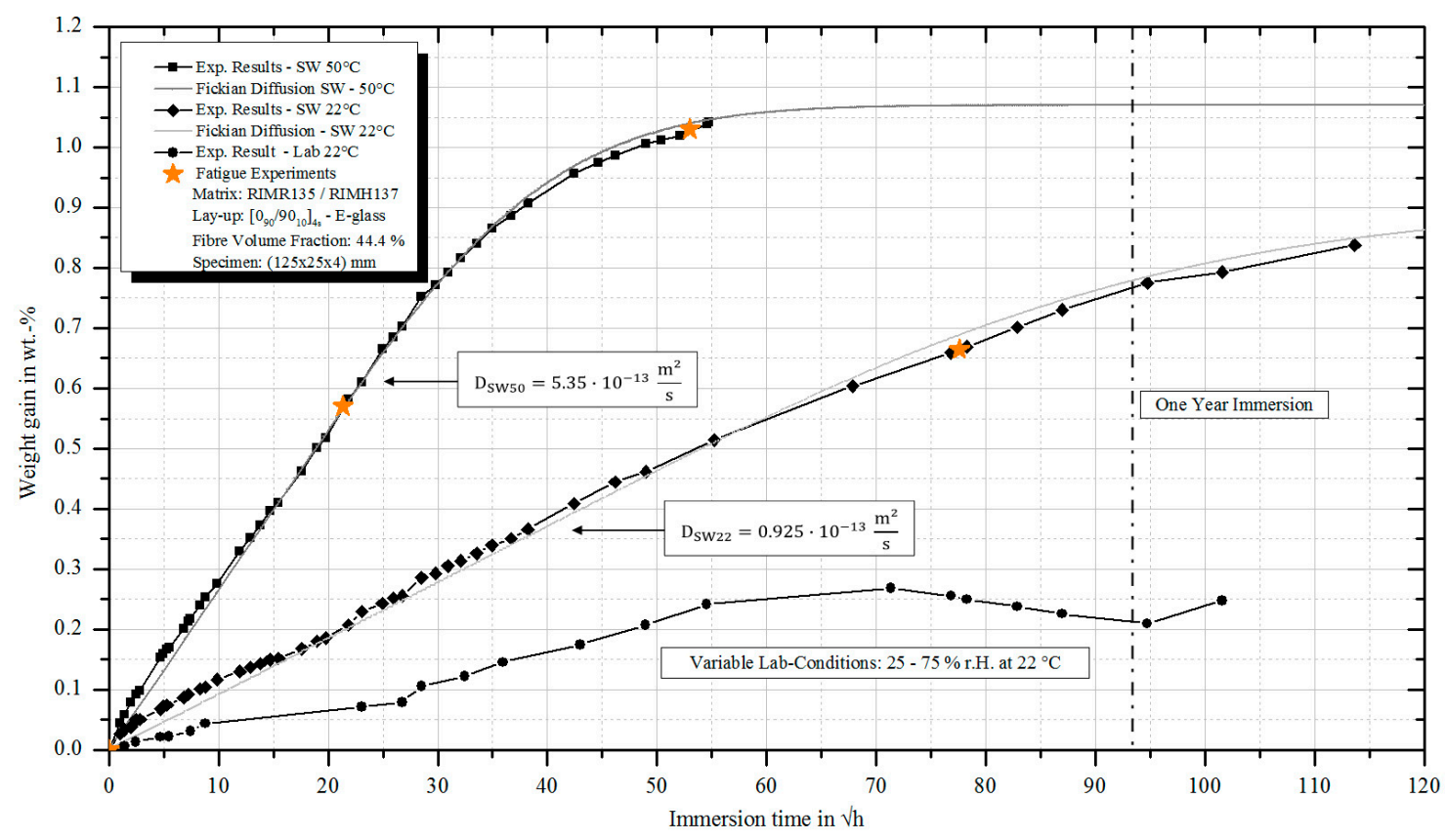

Figure 3. Absorption behaviour of the GFRP specimens at three environmental conditions. Moisture-dependent fatigue testing levels are highlighted with stars.

The diffusion coefficients displayed in Figure 3 can be used to examine the properties of the specimens with respect to the water absorption. Typically, the diffusion along the fibre direction is faster than transverse to it. As, for example, Rocha et al. [16] studied the direction-dependent diffusion behaviour of salt water immersed GFRP samples at $50^{\circ} \mathrm{C}$, comparisons can be made. Even though the fibre and matrix composition differ slightly, the good accordance of the diffusion coefficients of the presented specimen and the results published for a transverse diffusion direction is noticeable. 
Thus, it is assumed that the diffusion along the fibres and through the cutting edges did not have an excessive influence on the measurements. The highest deviations from the theoretical model according to (2) can be found during the first hours of water absorption and within the region close to the saturation level. While the former are probably the result of faster edge diffusion, the latter may be caused by locally variable fibre-matrix distributions, swelling effects, or fibre-matrix interphase effects. Nevertheless, it is well known that the diffusion behaviour of anisotropic FRP is not entirely represented by the simplification of one-dimensional diffusion as calculated by (2). In this context, investigations regarding the influence of the fibre-matrix interphase by Joliff et al. [35] identified an approximately five times faster diffusion within the interphase in comparison with the bulk resin. Also, Bond [36] pointed out that, for example, an irregular fibre distribution and the presence of resin rich layers between the plies might yield to deviations of the diffusion coefficients between models and experiments by up to $20 \%$. However, for the purpose of identifying weight change based material property effects, the simplification is sufficient in the present case. Using the diffusion coefficients calculated within the linear region of the water absorption curves, no further fitting was necessary.

During the water uptake, a regular visual inspection uncovered the formation of small opaque regions within the specimens after an immersion of about $1500 \mathrm{~h}$ in $50{ }^{\circ} \mathrm{C}$ salt water. Using optical microscopy, it was possible to correlate the opaqueness with the formation of fibre-matrix debondings around fibre bundles and cracks within these bundles. The amount of these defects increased further with time, whereby the distance between them decreased simultaneously. As presented in Figure 4, the distances between single defects can be less than $2 \mathrm{~mm}$ after immersion of nearly one year. Often, with more than $15 \mathrm{~mm}$, the distances between the first defects occurring are considerably larger, in contrast. A likewise behaviour of GFRP specimens has been observed by Gagani et al. [5], as well as by Rocha et al. [1,37].
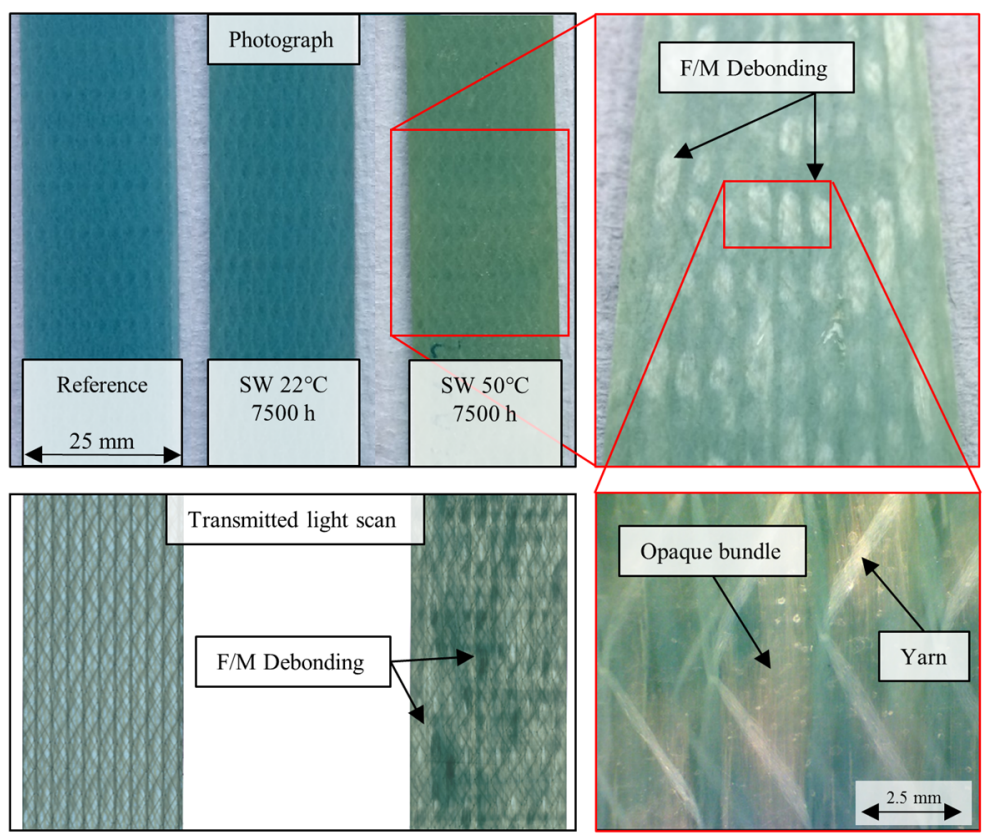

Figure 4. Comparative photographs and transmitted light scans of specimens unaged and after $7500 \mathrm{~h}$ of immersion. At $50{ }^{\circ} \mathrm{C}$, the formation of defects is clearly visible. F/M-fibre/matrix.

Additionally, a continuous change in colour was observed, which cannot be reversed by subsequent drying. This is expected to be a similar phenomenon to the yellowing of the same amine-epoxy type that Krauklis and Echtermeyer [38] were recently able to trace back to the carbonyl formation in the polymer backbone of the epoxy caused by thermo-oxidation. The extent to which the chemical reactions that cause discolouration have an effect on mechanical properties cannot yet be fully clarified. Investigations on dry, wet, and re-dried epoxy samples of Krauklis [39] (RIMR 135/RIMH 137) and 
Rocha [1] (RIMR 135/RIMH 1366) show to some extent contradictory results. While the former found neither a deterioration of the tensile strength and elongation at the break, nor of the E-modulus for re-dried specimens in comparison with the initial condition, the latter described a significant decrease in tensile strength and elongation at the break. As possible reasons for the brittle behaviour of the re-dried samples, Rocha et al. [1] mention both changes in the structure of the free volume and the formation of a secondary cross-linking due to the inclusion of water. Regarding the present study, the publications mentioned allow at least two conclusions to be drawn. Firstly, the extent to which the matrix properties of stiffness, strength, and elongation at the break change in the saturated condition can be identified. Secondly, it can be stated that hygrothermal ageing leads to chemical changes in the epoxy, which, however, do not have permanent negative effects on the mechanical properties in every case.

Remarkably, the immersion at room temperature of up to one year resulted in neither the formation of visible defects, nor a colour change of the same dimension. Representative samples showing debondings, cracks, and the colour changes after $7500 \mathrm{~h}$ of immersion are shown in Figure 4 . A more detailed microscopic investigation of these effects is given in Section 3.5.

\subsection{Tension-Compression Fatigue}

Firstly, the fatigue testing results indicate a significant influence of hygrothermal ageing on the fatigue life under reversed loading conditions, especially for saturated GFRP specimens. In fact, the water absorption impact on the fatigue life is load level, moisture content, and ageing time dependent. The immersion at an elevated temperature of $50^{\circ} \mathrm{C}$ up to saturation led to a decrease of the fatigue life for both the high and the low cycle fatigue regime. Particularly noteworthy is the reduction of the fatigue life in the high cycle fatigue range, as it was not presented before for unidirectional GFRP.

Resorting to the results of the preliminary investigation, it was possible to base the fatigue investigation on the horizon method. Therefore, five different horizons (load level) were chosen in order to cover fatigue lifetimes between $10^{4}$ and $10^{6}$ cycles. The applied loads covered a range from a maximum at $390 \mathrm{MPa}$ in tension and $195 \mathrm{MPa}$ in compression to $230 \mathrm{MPa}$ in tension and $115 \mathrm{MPa}$ in compression, which is equivalent to stress amplitudes between $292.5 \mathrm{MPa}$ and $172.5 \mathrm{MPa}$. A set of dry and wet aged fatigue results is presented in Figure 5 using stress amplitude $\left(\sigma_{a m p}\right)$ versus cycles to failure $\left(N_{f}\right)$ data points and a power law model (3) to fit the results in a log-log scale. All best-fit curves of the mean number of cycles $N_{50 \%}$ were evaluated according to

$$
\sigma_{a m p}\left(N_{f}\right)=A N_{f}^{b}
$$

where $A$ is the one cycle intercept and $b$ is the power law exponent, representing the slope of the SN-curve.

Because of a comparatively high scatter of almost two decades, additional tests were performed to increase the $\mathrm{SN}$-curve accuracy in the case of the long-term saturated specimens for an amplitude of $210 \mathrm{MPa}$. These data points are marked with supplementary rings in Figure 5. In all other tests, the scatter was within half a decade. Furthermore, it arises from the tests that a single power law fit according to (3) just inadequately represents the specimens conditioned up to saturation. Therefore, the SN-curve is split into two parts: one part representing the low cycle fatigue and the other one representing the high cycle fatigue region. With respect to a drastic decrease in static tensile strength in the case of saturated specimens (Section 3.4), it must be considered that the applied loads are comparatively higher in relation to the residual static tensile strength. Therefore, it must be assumed that the damage evolution in the low cycle fatigue region will differ from that in the high cycle fatigue region. With unidirectional FRP, the slope of the SN-curve typically flattens at loads close to the static strength. For example, Gamstedt and Talreja [40] reasoned that the damage development then is less progressive, but directly dependent on fibre failure. For this reason, the drastic reduction in fatigue life in the high cycle fatigue range $\left(<10^{4}\right.$ cycles) should not be overestimated. However, the absolute data 
represent a reduction in fatigue life by a factor of up to 50 in relation to the initial material strengths. From the user's point of view, this is, in any case, a serious finding. Moreover, the decrease is also comparatively higher, as others have described a factor of 5 to 10 so far $[4,23]$.

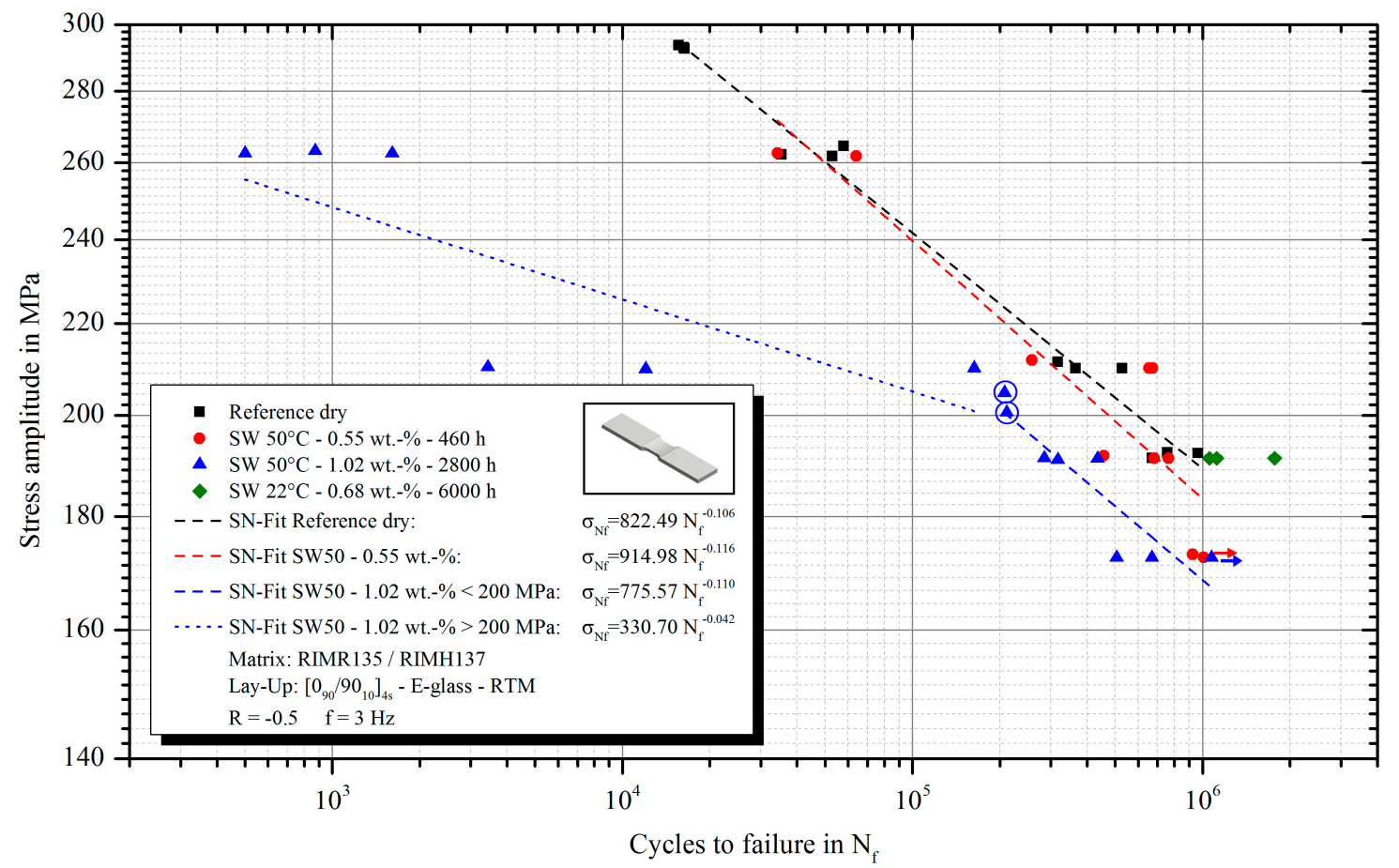

Figure 5. Results of the fatigue data under reversed $(\mathrm{R}=-0.5)$ loading and best-fit SN-curves of dry reference (black), as well as short- (red) and long-term (blue) immersed specimens in salt water at $50{ }^{\circ} \mathrm{C}$.

Because of the fact that tension-compression fatigue data after any kind of hygrothermal ageing for mainly unidirectional glass fibre epoxy systems do not exist in the literature, comparisons have to be drawn with tension-tension or compression-compression investigations, also including multidirectional laminates. Considering both the "SNL/MSU/DOE Composite Material Fatigue Database" and the "OptiDAT Database", as well as published results from Kennedy et al. [41], Dawson et al. [18], Mandell et al. [2,23], and Hu et al. [22], a two-part behaviour like that presented has not been observed before.

For mainly unidirectional GFRP laminates ( $91 \%$ of the fibres in $0^{\circ}$ direction), built up of an alike resin system and tested in fibre direction under tension loads $(\mathrm{R}=0.1)$, Mandell et al. [23] identified a load-dependent lifetime reduction for warm salt water $\left(50{ }^{\circ} \mathrm{C}\right)$ conditioned specimens as well. However, in contrast to the dataset presented here, there were differences and effects only limited to the low cycle fatigue regime $\left(<10^{4}\right.$ cycles). On this account, the authors reasoned consequentially that the unidirectional laminates are insensitive to seawater ageing in the high cycle fatigue regime. This is particularly remarkable as the static tensile strength of the material also decreased by up to $20 \%$ [2]. The results shown in Figure 5, in turn, indicate that this finding does not hold for the present case. A lifetime decrease is also evident within the high cycle regime in the case of reversed loading. In detail, the fatigue life of saturated specimens is still reduced by a factor of 2.5 at a stress amplitude of $191 \mathrm{MPa}$, which is close to the one million cycle lifetime of the reference. Because of the same slopes of the $\mathrm{SN}$-curves at this region, the load amplitude must then be reduced by almost $10 \%$ to achieve the same lifetime.

Contrasting the findings for saturated specimens, a short-term immersion, resulting in a lower content of absorbed water, obviously has just a marginal effect on fatigue life. The weight of the test specimens increased by an average of $0.55 \%$ during 19 days of immersion. Considering the different thicknesses due to the geometry and additional diffusion tests carried out on $2 \mathrm{~mm}$ and $4 \mathrm{~mm}$ thick 
specimens, it can be reasonably assumed that the moisture in the gauge length varies between $0.5 \%$ and a maximum of $0.8 \%$. Although this variance makes it more difficult to assess the individual effects, an inhomogeneous moisture distribution represents most of the components in applications. It is known that an inhomogeneous moisture distribution leads to additional stresses between dry and humid regions. Nevertheless, these additional stresses have not shown measurable influences on the fatigue life. Within the range of the study, no difference can be found between the fatigue performance of the dry and the short-term aged configurations. Negative effects of water exposure, which reduce the fatigue performance, are accordingly limited to the saturated specimens or a longer time of exposure. As no visible defects (Figure 4) were identified after the shorter immersion, in contrast to the saturated specimens, it is assumed that especially this moisture related pre-damage is of decisive importance. Considering an additional set of samples, tested at stress amplitudes of $191 \mathrm{MPa}$ following immersion of $6000 \mathrm{~h}$ (250 days) in artificial seawater at room temperature, even a fatigue life increase is observable. Summarising the results, there is evidence to suggest that there is a complex relationship between the exposure duration, temperature, and amount of absorbed water with respect to the fatigue performance.

When considering possible reasons for the fatigue performance, it can be assumed that load-dependent different modes of damage play a main role. Hygrothermal ageing can have an influence on various composite properties. For example, fibre, matrix, and interphase strength may decrease, while matrix toughness and elongation at the break may also increase. Helpful in this context are the investigations of Castro [42] and Zangenberg [43], characterising the fatigue failure behaviour of unidirectional GFRP. By continuously evaluating microscopic recordings of fatigue specimen surfaces, Castro et al. [42] determined the fatigue damage evolution under tensional loads. They showed that typically, early fibre failures during the first cycles are the first defects that occur. Subsequently, interphase (fibre/matrix) debondings tend to start and develop directly from the tip of the fibre breaks, as a consequence of high shear stresses. If the stresses applied are high enough, these debondings will grow and lead to further fibre failures. Otherwise, they will stop and no further damage is expected. In the case of humid ageing, it is suggested now that both the glass fibre strength and the matrix and interphase shear properties directly influence the results. While a decrease of the fibre strength might lead to more fibre failures even at lower loads, a decrease of the matrix and interphase shear strength, on the other hand, will facilitate the growth of debondings and delaminations. When these damage types combine locally, a final failure of the specimen is probable. Furthermore, both authors showed that fibre breaks, as well as interphase debondings, occur more frequently in regions where backing fibres or stitching threads run transversely to the load direction inside the laminates [42,43]. In the present case, this phenomenon is expected to even be amplified at the saturated condition by the immersion induced fibre-matrix debondings. In dependence of the applied load level, it is suggested that the debondings will promote early fibre failure due to stress localisation at high loads, whereas at lower stresses, mainly the initially faster-growing defects and defect connections decrease the fatigue performance. As the reversed loading also includes a compressive loading part, further damage will arise, as has been previously investigated by Gamstedt and Sjörgreen [44] on micromechanical investigations. Especially around the transversal fibres, it can be expected that the alternating loads result in an increase of debonding angles between fibres and matrix, as well as an increase of the transverse crack length compared with pure tensile loads. In case of extensive fibre-matrix debondings, a micro-buckling of the fibres in loading direction also cannot be excluded. Given that even for low stresses, no overlapping of the dry and saturated curves occurs, hygrothermal effects should consequently be taken into account, for applications where alternating loads are feasible, especially when elevated temperatures and pre-existing damages might appear. 
Taking the additional results after ageing at room temperature into account, the question also arises whether an increase in temperature is permissible in order to make statements about the fatigue performance of composites at ambient outdoor conditions. Guzman and Brøndsted [4] published the only comparable study dealing with the effects of wet ageing at room temperature in the context of the OPTIMAT project. Similar to the present case, the authors noted a slight increase in fatigue performance after exposure of one year. A set of five additional specimens tested another seven years later showed on the other side that years of exposure mainly led to impairment under high loads as well. In order to achieve the goal of significantly reducing the test duration, future investigations will have to deal with the relationships between exposure time and temperature in particular. Otherwise, just considering worst-case scenarios, high safety factors must continue to be applied.

\subsection{Details of Fatigue Testing after Hygrothermal Wet Ageing}

Regarding common literature characterisations $[45,46]$ for the fatigue life behaviour of typical unidirectional composites, for example, those used in rotor blade applications, the results obtained with the new test specimens are well comparable. In particular, the slopes of the best-fit SN-curves, as well as the composites strength, stiffness, and ply structure, are of the same magnitude. Similar $\mathrm{SN}$-curve slopes of about 0.1 have been presented for fatigue tests of various GFRP specimens as well [45]. The specimens presented here are also characterized by a very low scattering, both in the high cycle and in the low cycle fatigue regime, which allows identifying differences caused, for example, by hygrothermal ageing.

During the development of the test specimens, analytical methods were used to investigate the damage behaviour. These were mainly fracture analysis, passive thermography, and monitoring of the damage process in terms of the stiffness reduction. As shown in Figure 6, the newly designed samples typically showed three different failure patterns. While two of them $(a, b)$ had the desired failure within the free test length, some continued to show their final failure within the clamping area (c). The analysis of the fracture surfaces indicates a change of the dominant damage mechanism in dependence of the stress level. It is assumed that at high stresses, progressive fibre failure in combination with fast-growing delaminations leads to failures of type (a) and (b) within the free gauge length. In these cases, the fracture patterns of the failed specimens show either straight or diagonal continuous cracks, with the final failure always occurring under tensile loading. It is noticeable that the lower the loads and the higher the number of load cycles, the more likely it is that final failure damage will occur in the clamping area. If that happens, it is hypothesized that two mechanisms act primarily. On the one hand, delaminations starting in the gauge section will grow between plies in the direction of the clamping and, on the other hand, interfibre fractures (splitting), starting from the radii of the gauge length, will also grow in the same direction. Because of the low stresses, both damage types can then combine beneath the clamps before enough critical fibre damages occur within the free test length to cause a final failure. An explanatory schematic representation is given in Figure 6d.

In addition, it can be assumed that moisture-induced fibre-matrix debondings, as well as a strongly decreased interlaminar shear strength (Section 3.4), affect the fatigue performance of the saturated specimens. Both effects are suggested to promote the formation of large-area delaminations starting at crossing backing fibres, as they have only been identified for the saturated sample. The disrupted interfacial strength will consequently lead to a reduction in fatigue life due to the reduced load transfer capacities. Furthermore, thermography has revealed that the first visible defect is most often the starting point for the final failure. Significant warming could only be detected locally around these occurring defects.

The comparison of the elastic stiffness developments and the fracture surfaces was used to identify differences between the tested configurations. As the stiffness measurement is based on the machine displacement, the results should only be used for comparison purposes. It should be noted that this type of measurement also includes the machine and the gripping region, but this holds equally for dry and wet samples. Therefore, although it cannot be excluded that stiffness may be affected by damage 
outside the gauge length, the normalised presentation clearly shows characteristic differences between the tested configurations. It has been found that the initial damage progress is significantly greater with wet specimens, regardless of the load level. As represented in Figure 7, the first drop in elastic stiffness of saturated specimens usually proceeds about two times faster than for dry specimens. However, as the initial stiffness is the same, it can be assumed that the ability to withstand a formation and growth of first inter fibre fractures, delaminations, and fibre fractures is reduced. The reasons for this effect may include ageing-related reduced fibre, interphase, and shear strength. After reaching the second phase of fatigue life, the degradation levels for all specimens remain similar. A distinction between the configurations is no longer possible at this point. In the case of the saturated specimens, though, the final failure occurs much earlier and very suddenly. Therefore, it is assumed that the occurrence of further fibre fractures leads to local stress concentrations that cannot be transferred to sufficient surrounding fibres as a result of reduced interphase and shear strength. The assumption is furthermore supported as investigations on interlaminar stressed GFRP, presented by Rocha [1] and Gagani [5], also indicate a significant decrease of the fatigue performance after hygrothermal ageing. In the case of the dry reference and the moderately aged specimens, more local defects can be withstood. As shown schematically in Figure 7 based on the test data, dry reference specimens typically exhibit two stiffness drops that also influence the slope of the degradation curve before the final failure occurs. Lastly, the final failure of the saturated specimens proceeds significantly faster. Whereas the saturated exhibit a very spontaneous failure within less than 500 cycles, this progress can be observed over several thousand cycles for the dry ones. In particular, the sudden failure must be considered critically for various applications. As damage monitoring in composite components is very difficult anyway, the influence of moisture is a major factor that should be taken into account to ensure safe use.
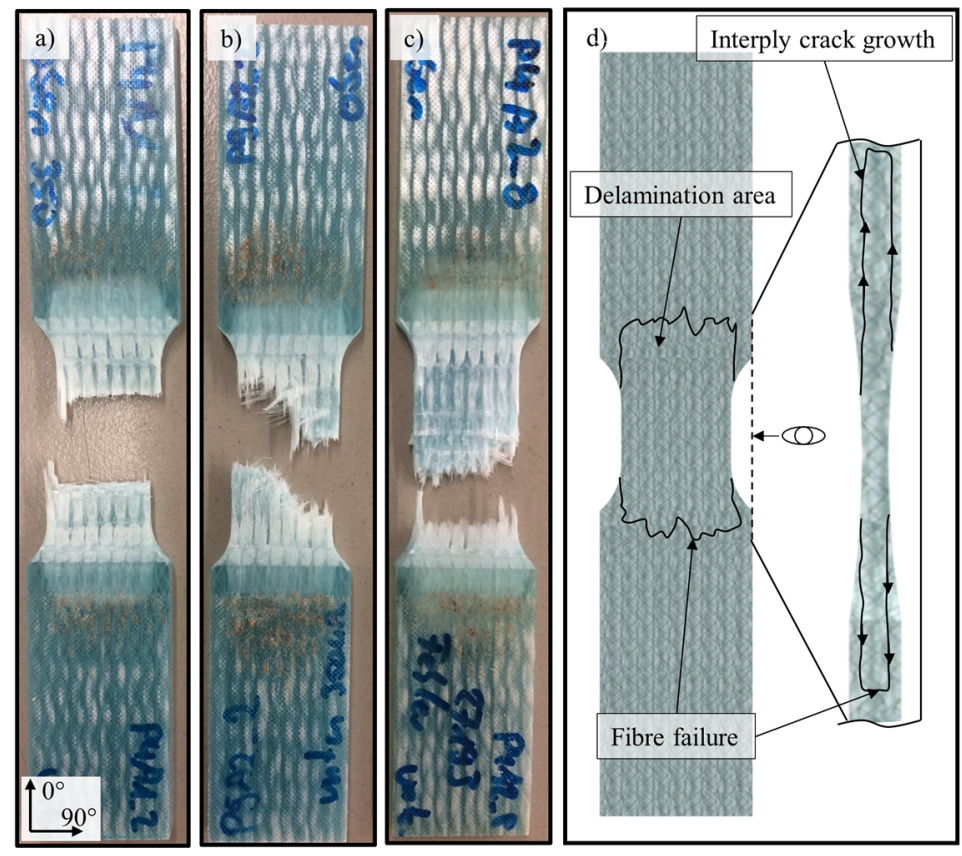

Figure 6. Typical failure modes of fatigue specimens. Final straight (a), diagonally (b), and shifted interply (c) failure. Scheme of delamination and interply crack growth regions and directions (d). 


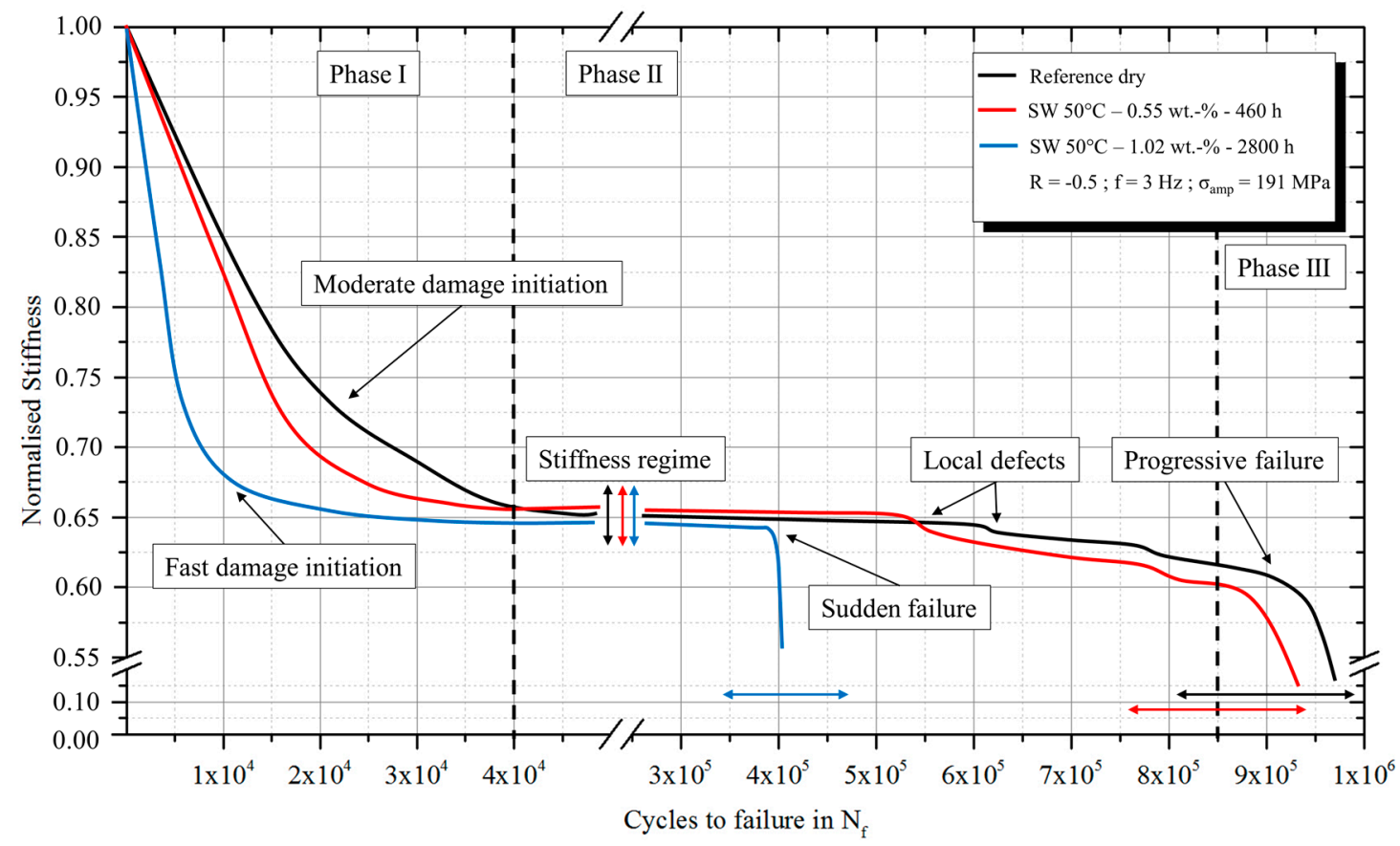

Figure 7. Schematic representation of the stiffness development during the fatigue test based on a load amplitude of $191 \mathrm{MPa}$. The exact values of stiffness and life may vary for each sample. The diagram illustrates the general trends.

\subsection{Hygrothermal Effects on Static Mechanical Properties}

Mean tensile, bending and shear strength, elastic moduli, strains to failure, and the failure characteristics were determined at defined points in time. The resulting amount of data makes it possible to analyse the effects of immersion on the composite for a variety of loading cases. The changes in the respective properties can be plotted either individually over the duration of exposure or combined as a function of the current water content for a specific point in time. The results shown in Table 3 indicate a negative influence for every examined environmental ageing condition and duration concerning ultimate strength and strain at failure. As expected, the largest reduction of these mechanical parameters could be observed in saturated specimens after ageing at $50{ }^{\circ} \mathrm{C}$. In this case, both failure stress and failure strain were reduced by up to $49 \%$. Tests were executed on aged specimens directly after taking them out of the water bath.

Table 3. Influence of variable wet ageing conditions and durations on the static mechanical properties of the glass fibre reinforced polymer (GFRP) laminate. * The dry four-point bending samples showed incorrect failure beneath the upper supports. Reference bending strength is expected to be higher than measured.

\begin{tabular}{|c|c|c|c|c|c|c|}
\hline Investigation & Dry & $\begin{array}{l}\mathrm{SW} 50^{\circ} \mathrm{C} \\
0.3 \mathrm{wt} . \%\end{array}$ & $\begin{array}{l}\text { SW50 }{ }^{\circ} \mathrm{C} \\
0.6 \mathrm{wt} . \%\end{array}$ & $\begin{array}{l}\text { SW50 }{ }^{\circ} \mathrm{C} \\
\text { Saturation }\end{array}$ & $\begin{array}{l}\text { SW50 }{ }^{\circ} \mathrm{C} \\
\text { Re-Dried }\end{array}$ & $\begin{array}{l}\text { SW22 }{ }^{\circ} \mathrm{C} \\
0.3 \text { wt. } \%\end{array}$ \\
\hline $\begin{array}{c}\text { Tensile strength in } \\
\mathrm{MPa}\end{array}$ & $893 \pm 31$ & $\begin{array}{l}838 \pm 23 \\
(-6.2 \%)\end{array}$ & $\begin{array}{l}764 \pm 17 \\
(-14.4 \%)\end{array}$ & $\begin{array}{l}468 \pm 11 \\
(-47.6 \%)\end{array}$ & $\begin{array}{l}601 \pm 10 \\
(-32.7 \%)\end{array}$ & $\begin{array}{l}790 \pm 15 \\
(-11.5 \%)\end{array}$ \\
\hline $\begin{array}{l}\text { Tensile failure strain } \\
\text { in } \%\end{array}$ & $2.96 \pm 0.08$ & $\begin{array}{c}2.78 \pm 0.05 \\
(-6.1 \%)\end{array}$ & $\begin{array}{c}2.57 \pm 0.09 \\
(-13.2 \%)\end{array}$ & $\begin{array}{c}1.51 \pm 0.04 \\
(-49.0 \%)\end{array}$ & $\begin{array}{c}1.96 \pm 0.02 \\
(-33.8 \%)\end{array}$ & $\begin{array}{c}2.61 \pm 0.06 \\
(-11.8 \%)\end{array}$ \\
\hline $\begin{array}{l}\text { Tensile elastic } \\
\text { modulus in GPa }\end{array}$ & $33.0 \pm 0.68$ & $33.1 \pm 0.61$ & $32.8 \pm 0.37$ & $32.5 \pm 0.27$ & $32.5 \pm 0.42$ & $33.0 \pm 0.12$ \\
\hline $\begin{array}{l}\text { 4-p bending } \\
\text { strength in } \mathrm{MPa}\end{array}$ & $860^{*} \pm 23$ & $\begin{array}{l}812 \pm 12 \\
(-5.6 \%)\end{array}$ & $\begin{array}{l}743 \pm 22 \\
(-13.6 \%)\end{array}$ & $\begin{array}{l}595 \pm 22 \\
(-30.8 \%)\end{array}$ & I & I \\
\hline $\begin{array}{l}\text { ILSS strength in } \\
\mathrm{MPa}\end{array}$ & $45.9 \pm 0.92$ & $\begin{array}{c}44.3 \pm 1.94 \\
(-3.5 \%)\end{array}$ & $\begin{array}{c}39.5 \pm 3.88 \\
(-13.9 \%)\end{array}$ & $\begin{array}{c}31.9 \pm 4.37 \\
(-30.5 \%)\end{array}$ & l & I \\
\hline
\end{tabular}


In addition to the worst case of complete saturation, the relationship between exposure time, water content, and mechanical properties is of particular interest. Figure 8 , therefore, illustrates the material tensile strength in dependence of the duration of immersion at $50{ }^{\circ} \mathrm{C}$ salt water and amount of water uptake, as an example. If the tensile strength is represented as a function of the square root of immersion time, a linear relationship results in a good approximation at least up to a moderate duration of $1680 \mathrm{~h}$ (70 days). By the simultaneous representation of the uptake water amount, it becomes clear that the tensile strength depends not only on this water amount, but in particular on the duration of the immersion. The comparison of samples stored for short periods at different temperatures also confirms this finding. As there are also very similar dependencies for the bending and shear strengths, the wide investigation of the composite allows a good prediction of the mechanical properties as a function of the ageing conditions.

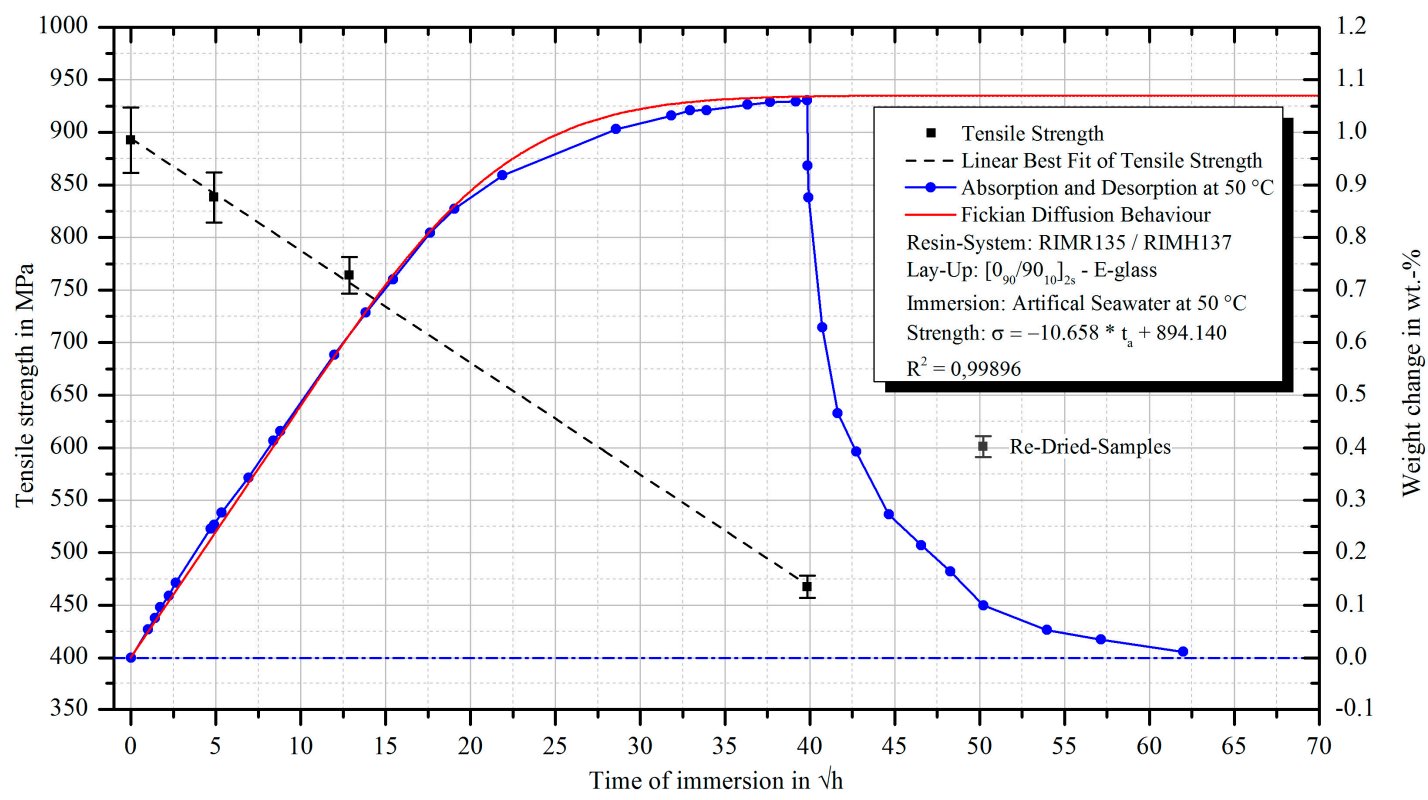

Figure 8. Tensile strength (black) in dependence of the immersion duration and amount of absorbed water at $50{ }^{\circ} \mathrm{C}$ (blue). Additionally, the effect of desorption for partial recovery of the tensile strength and the theoretical diffusion behaviour according to (2) is depicted (red).

Remarkably, although the amount of water absorbed is identical at $0.3 \%$, the tensile strength of the specimens conditioned at room temperature is about $50 \mathrm{MPa}$ lower than that of the specimens stored at $50{ }^{\circ} \mathrm{C}$. Because of this result, which cannot be expected at first glance, it becomes clear that the approximately 10 times longer duration of immersion can have an impact on the strength, which should not be underestimated. In order to make it easier for users to select materials in the future, material parameters should also be determined under severe conditions like moisture saturation or application-related temperatures. For this, however, it is necessary to investigate up to which temperature-induced acceleration physically realistic material parameters can be generated.

The evaluation of the tensile stress-strain curves presented in Figure 9 shows only very little differences (except for the strength and strain to failure) between the tested reference and aged conditions. Whereas there is no difference within the beginning of the elastic region of at least up to $1 \%$ strain, the hygrothermal ageing leads to a slight decrease of the slopes for higher strains. Furthermore, the decrease of the slopes seems to increase slightly with an increasing amount of absorbed moisture. As fibres dominate the stiffness of unidirectional GFRP composites, it can be assumed that the decrease in stiffness can be related to an increasing number of fibre failures. Nevertheless, it is not possible to certainly determine from the results to which extent a possible decrease in fibre strength or a possible deteriorated stress distribution, due to weaker interphase and shear properties, cause these effects. 


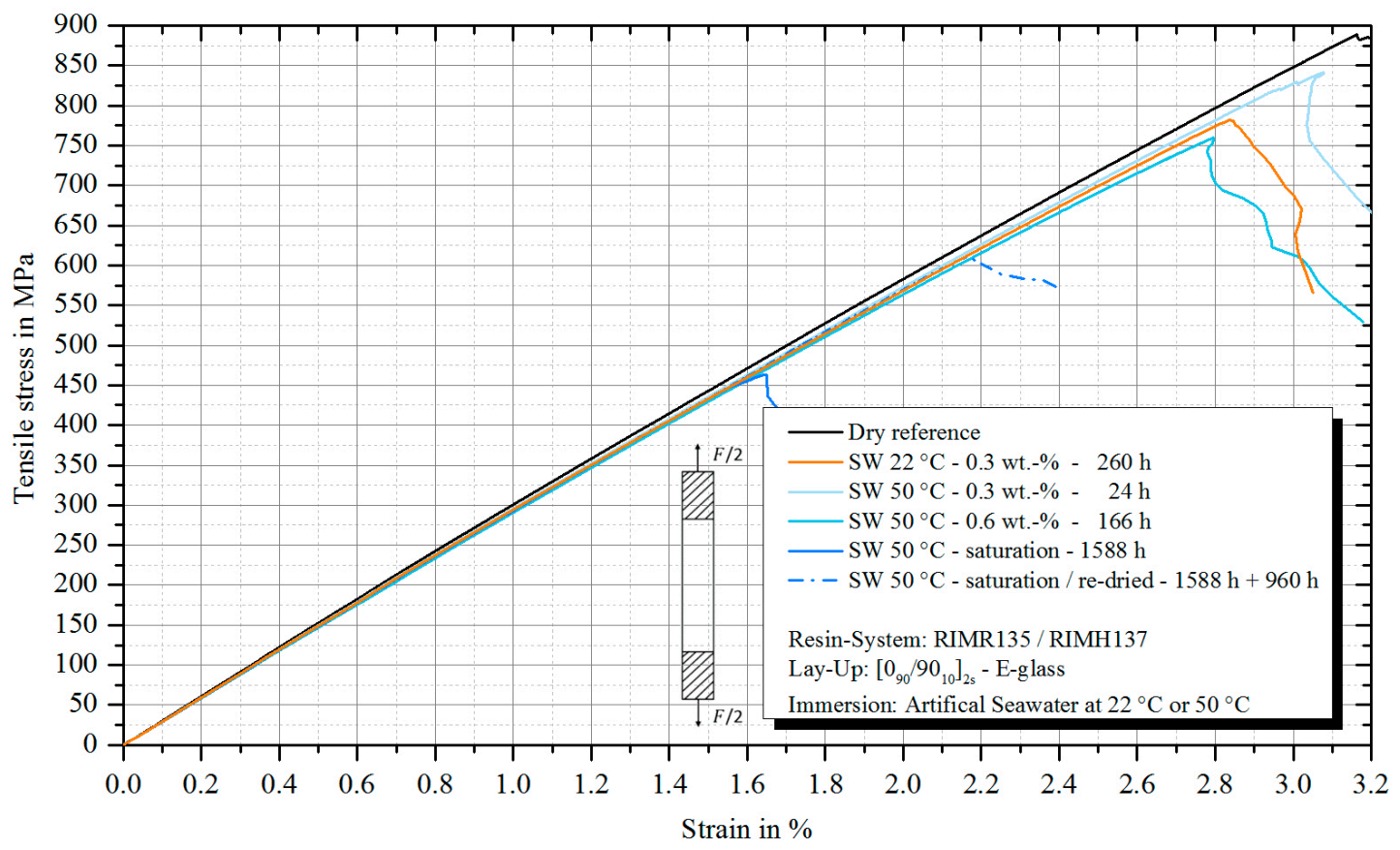

Figure 9. Stress-strain curves of representative tensile tests on dry reference and hygrothermally aged specimens. Strains were measured using an extensometer within the free gauge length.

The fracture analysis offers a tool to identify effects due to the negative influence of ageing conditions on the composites. First and foremost, it is noticeable that the fracture surface areas of the tensile specimens decrease significantly with a longer duration of immersion. This phenomenon might be a consequence of several effects taking place by reason of hygrothermal ageing. It is suggested that all the fibre strength and constitution [47,48], the matrix strength and stiffness [39], as well as the fibre-matrix interphase properties [37,49] suffer by moisture immersion. Reductions in fibre strength are typically caused by leaching of soluble elements [47], which can lead to the phenomenon of stress corrosion cracking under the presence of tensile stresses. As the matrix surrounding the fibres should protect the fibres generally from direct water contact, it is assumed that stress corrosion cracking has a minor influence as long as the fibres are well embedded in the matrix. For the present study, this is the case for all samples tested, except for the saturated ones. As has been shown in Figure 4 the long-term immersion at $50{ }^{\circ} \mathrm{C}$ causes fibre-matrix debondings and flaws, which are assumed to fill with water as well, resulting in a direct water contact of the fibres. The decrease in tensile strength of the composite is thus assumed to also be affected by a decreasing fibre strength (of at least a proportion of the fibres) over time. The epoxy matrix, on the other hand, according to Krauklis et al. [39], is expected to degrade in terms of strength up to $25 \%$ and stiffness up to about $10 \%$. A decrease in matrix stiffness can also reduce the composites' interfacial shear strength significantly, as identified by Rao and Drzal [49]. Because of this reduction of properties, especially locally high stresses around fibre breaks or fibre-matrix debondings of the transverse fibres are suggested to result in more severe defects locally. Furthermore, the presence of water inside the interphase is expected to destroy the strong covalent bonds between the silane coupling agents and the matrix, as well as reduce secondary molecular forces over time [50]. Additionally, as the interlaminar shear properties (strength and stiffness) of the composite also suffer noticeably (Table 3), the stress transferability between the fibres will decrease as well. Although a weak interphase might be expected by shear lag theory to increase the fracture surface area [51], the opposite is found after hygrothermal ageing in the present study. One reason for this difference might be that shear lag theory is based on the assumption of a pure unidirectional fibre orientation, which is not the case for the composite investigated. Another reason might be that more effects are taking place caused by hygrothermal ageing than only a change of the interphase properties, as discussed previously. Additionally, taking into account the microscopic fracture surfaces presented 
in Figure 10, it is clearly visible that the matrix stripped off extensively from the fibres after long-term immersion. Consequently, it is suggested that this is caused by the fibre-matrix interphase degradation with moisture absorption. A combination of earlier (stress-related) fibre breaks, a weakened matrix strength and stiffness, as well as a significant decrease in interphase strength is suggested to result in the localisation of the defects, leading to a drastic reduction in tensile strength and smaller fracture surfaces. As a decrease in strength can be found a long time before visually detectable fibre-matrix debondings occur, it is most likely that the decrease in static properties is related to a progressive weakening of interphase and matrix properties, which finally end in local debonds.

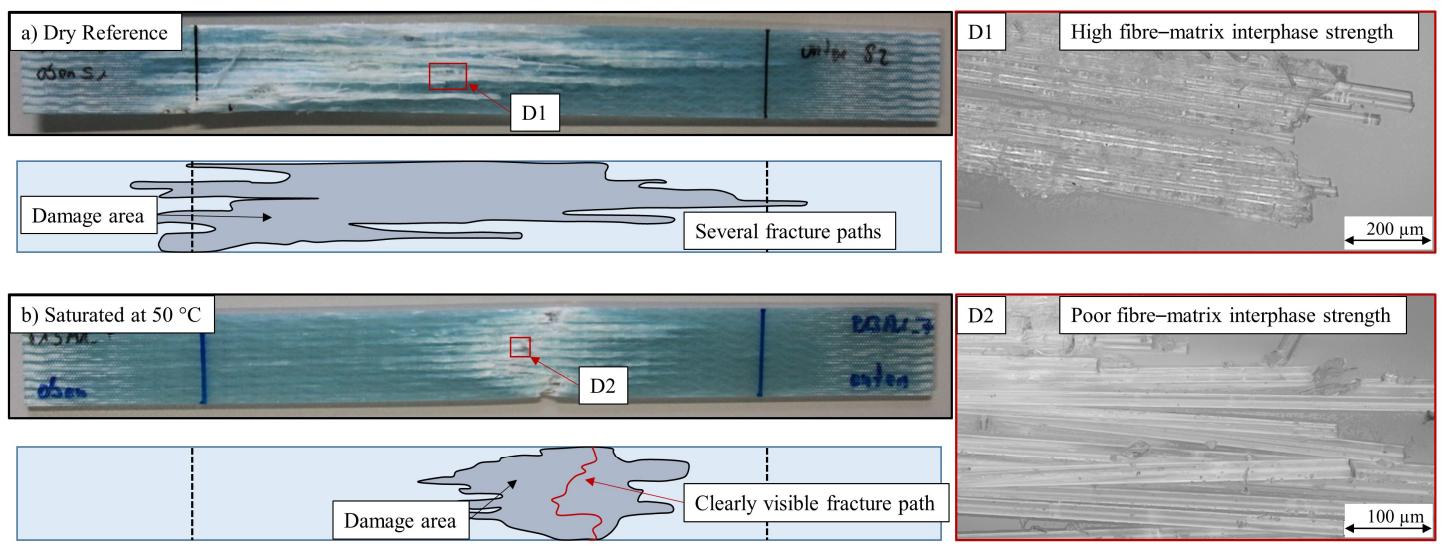

Figure 10. Photographs, micrographs, and schemes of the fracture area after static tensile tests. The damage area and the fibre-matrix bond strength decrease significantly with hygrothermal ageing.

Re-drying tensile specimens at $50{ }^{\circ} \mathrm{C}$ vacuum for 94 days results in nearly complete water desorption, where only $0.01 \mathrm{wt} . \%$ remain inside the composite. Nevertheless, the tensile strength remains at a level about 33\% lower than in the initial dry state. The tensile strength increase of $15 \%$ in comparison with the saturated state might be mainly attributed to the ability of the matrix to regain its mechanical strength and stiffness to a large extent [39]. For the same amine epoxy matrix resin used within this work, Krauklis et al. [39] pointed out that the static tensile and fatigue properties are almost reversible by re-drying after hygrothermal immersion to saturation at $60^{\circ} \mathrm{C}$. Therefore, the experimental outcome supports the hypothesis that possible fibre and moisture-induced interphase degradation leads to irreversible damage inside the unidirectional GFRP laminate, which consequently reduces the composite strength. Taking also into account the possibility of dissolution of the water attractive parts of the glass fibre sizing, interphase degradation might play an equal role as fibre degradation. This assumption is also supported by Rocha et al. [1], who identified a permanent loss of the interphase and matrix dominated interlaminar shear strength of the same magnitude, as identified for the tensile strength present. As the matrix properties provide a minor contribution to the tensile strength of unidirectional laminates, it is reasonable to assume that under re-dried conditions, the negative changes within the fibres, interphase, and already existent fibre-matrix debondings are mainly responsible for the irreversible degradation. For further investigations, the question remains of how the composite properties are affected when specimens are re-dried before the saturation level is reached. In addition, it has to be clarified whether there is a threshold, either in terms of temperature or moisture content, at which degradation becomes permanent.

In the future, it would make sense to plot the changes in material properties caused by hygrothermal ageing in the form of cobweb diagrams. These allow the performance of different composites to be easily compared across conditioning conditions. For example, this is shown in Figure 11 for the investigated GFRP during conditioning at $50{ }^{\circ} \mathrm{C}$ salt water for three water contents. 


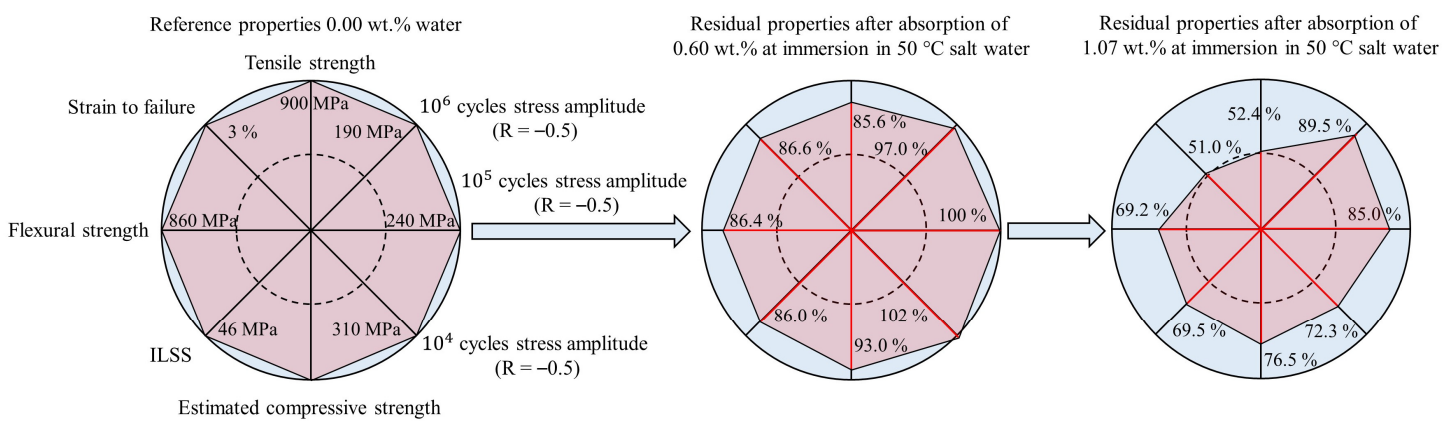

Figure 11. Cobweb diagram visualisation of the development of the mechanical properties as a function of the amount of absorbed water due to immersion in salt water at $50^{\circ} \mathrm{C}$.

\subsection{Material Characterisation and Microscopic Observations}

The use of optical and scanning electron microscopy (SEM) allows identifying differences within the fracture surfaces of tested samples that may provide an indication of which defect mechanisms are acting. For the investigated conditions, SEM microscopy uncovers extensive fibre-matrix interphase debondings at the fracture surfaces of static and fatigue samples in the case of hygrothermal exposure, as illustrated in Figure 12. In comparison with dry specimens, conditioned specimens show extensive detaching of fibres from the surrounding matrix after failure. This supports the thesis that at high loads, the plasticised interphase is the main reason for the reduced strength. In the case of the fatigue tests, the weak interphase leads to the growth of extensive delaminations, as SEM uncovers explicitly. These delaminations, therefore, are expected to be the main reason for significantly shortening the fatigue life.

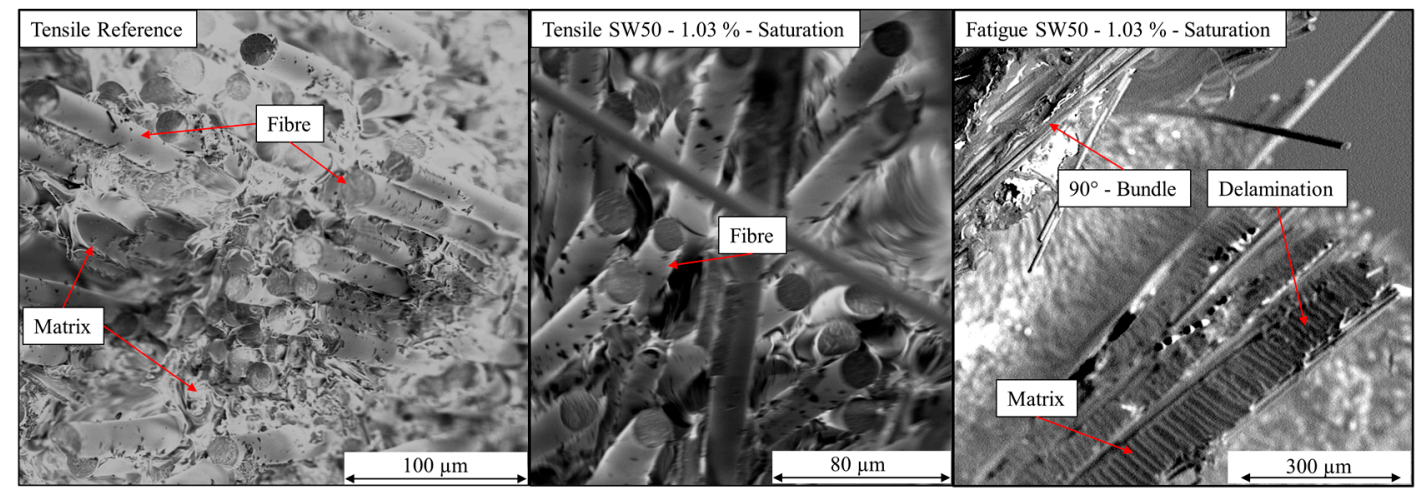

Figure 12. Scanning electron microscopy (SEM) photograph of fracture surfaces of the tensile specimens in dry (left) and saturated (middle) conditions, as well as the fatigue fracture surface in saturated condition (right).

Optical microscopy is used to exclude manufacturing defects and analyse the moisture ageing effects. In this way, it is possible to assign the changes visible to the eye in the composite, as shown in Figure 4, to large-area fibre-matrix debondings. These detachments occur as a result of matrix swelling and a simultaneous reduction of interphase strength. In addition, it can be seen that the debondings mainly affect the fibre bundles and that they start near matrix rich areas. The micrographs in Figure 13 show the extent and location of the debondings within the cross-section of a laminate after immersion at $50{ }^{\circ} \mathrm{C}$. Moisture-induced fibre-matrix interphase detachments have similarly been discovered by Grace et al. [52] in a long-term diffusion study at $25^{\circ} \mathrm{C}$ after five years of immersion. Consequently, it can be assumed that the detachments are less temperature-dependent, but much more dependent on the amount of water absorbed. Whether and when a defect occurs depends moreover mainly on the fibre-matrix combination and the durability of the formed interphase. In the future, it has to be clarified how this damage process is dependent on elevated temperatures and high absorption contents. 

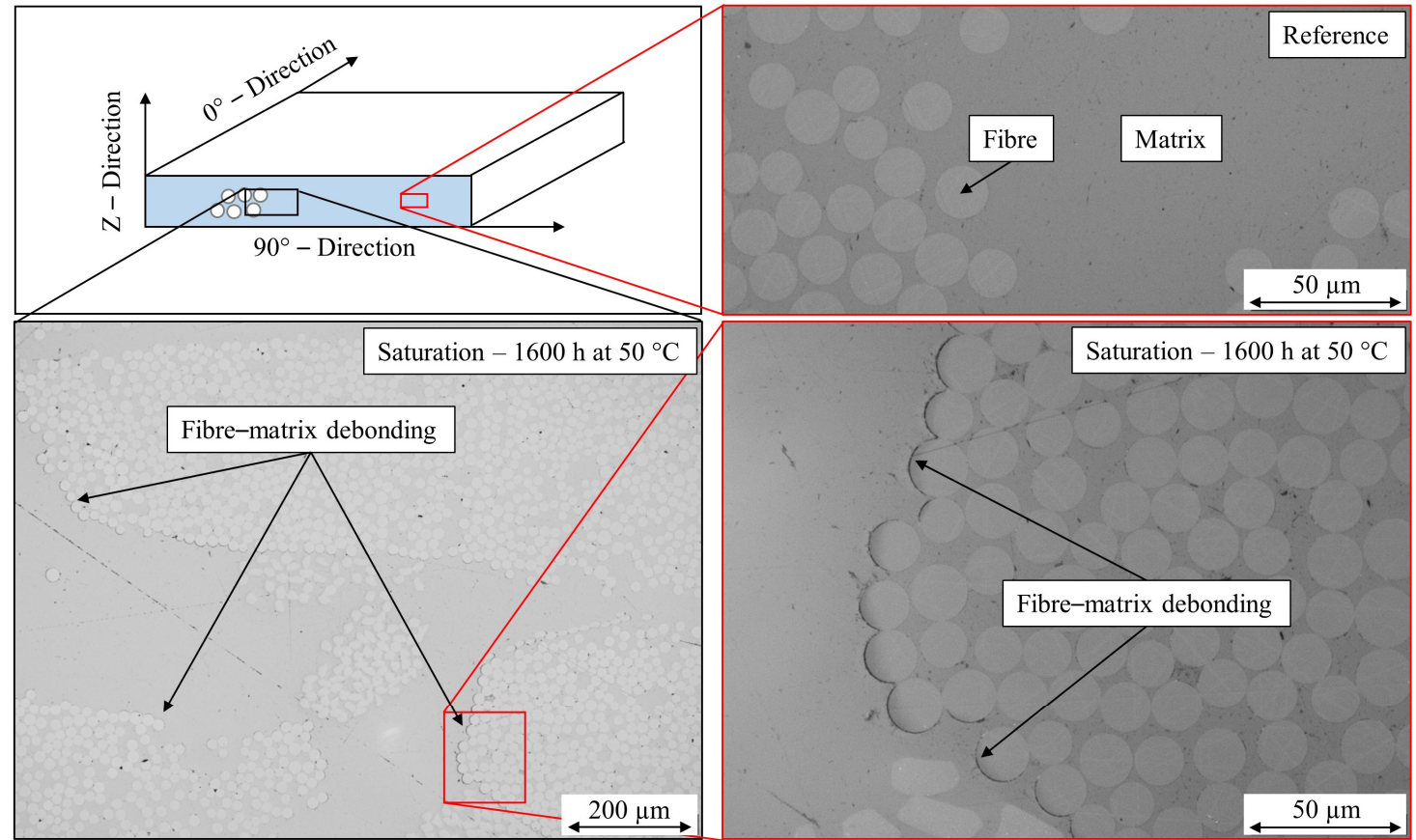

Figure 13. Optical micrographs of laminate cross sections at the initial state (top) and after immersion in salt water at $50{ }^{\circ} \mathrm{C}$ for $1600 \mathrm{~h}$ (bottom). The long-term immersion leads to extensive fibre-matrix debondings along the outer fibres of a single bundle.

\section{Conclusions}

This work has reported a wide study of hygrothermal degradation of GFRP composites. The main findings are listed as follows:

1. A significant reduction of fatigue life under cyclic tension-compression loads has been identified depending on the load and immersion duration. By applying an improved unidirectional glass fibre epoxy composites specimen geometry, it was possible to generate fatigue test results that are not influenced by early gripping failure due to excessively warming. It was also possible to perform the tests without anti-buckling devices. It has been shown that the mechanisms leading to a drastically reduction of lifetime were to a large extent connected to the fibre-matrix interphase and shear properties. These are decreasing with an increasing amount of absorbed water, as well as an increasing immersion duration and temperature. The load level dependent two-part behaviour of hygrothermally aged GFRP specimens is suggested to be a result of different damage mechanisms acting. While possible hygrothermal ageing-related fibre damage and the plasticized interphase leads to rapidly growing fibre-matrix debondings, delaminations, and fibre failures at high loads, the more severe initial damage predominates at low loads. In contrast, a minor and partial water uptake has shown only a negligible influence on the fatigue life. Consequently, it could be assumed that a minimum content of water has to be present within the composite in order to cause a fatigue life reduction. This demonstrates to some extent a resistance against hygrothermal ageing of the composite.

2. The detected fatigue life increase for room temperature immersed specimens provided reasons to further investigate the validity of accelerated absorption tests under elevated temperatures when conclusions have to be drawn for applications at room temperature. The fatigue results, which are in good accordance with the results achieved within the OPTMAT project, furthermore confirm the hypothesis that especially the interphase durability is the dominating factor. For composite materials used in maritime applications, it must be ensured that no fibre-matrix debonding occurs as a result of swelling stresses and decreasing interphase strength, as has been detected within this study. Further investigations on fibres and model composites as, for example, fibre bundle tests 
or fragmentation tests, are thus required in order to better understand the underlying processes regarding the degradation of fibres and interphases. With the help of this information, further conclusions can be drawn, in particular, to be able to reconstruct the effects during fatigue testing.

3. Testing the dependence of static material properties on the absorbed amount of water, a negative influence on the static tensile, flexural, and interlaminar shear strength has been proven for every type and duration of conditioning. In contrast to the fatigue results, the moisture absorption decreases these properties from the outset. A summary of the performed tests, as presented in form of cobweb diagrams in Figure 11, allows an estimation of the major composite properties in dependence of the ageing exposure and will be a helpful tool for future component design.

Author Contributions: Conceptualization, D.G. and A.D.; methodology, D.G.; formal analysis, D.G.; investigation, D.G. and A.D.; writing-original draft preparation, D.G.; writing—review and editing, A.D., B.F., and L.M.; visualization, D.G.; supervision, B.F. and L.M.; funding acquisition, B.F. and L.M.

Funding: This work was carried out with funding from the German Research Foundation (DFG) within the project number FI 688/4-1 and the Federal Ministry for Economic Affairs and Energy (BMWi) within the AIF project number ZF4563401. This financial support is gratefully acknowledged.

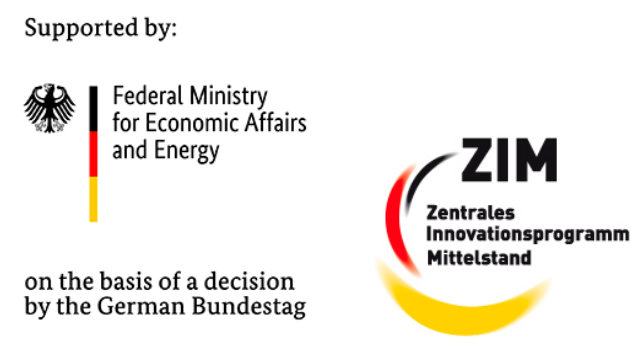

Acknowledgments: The authors would like to express their thanks to Jörg Spitzner and Alexander Backs from Spitzner Engineers $\mathrm{GmbH}$, and Abedin Gagani for the valuable and inspiring discussions on the topic.

Conflicts of Interest: The authors declare no conflict of interest.

\section{Appendix A}

In the following figure, detailed schematic representations of the accomplished tests are illustrated.

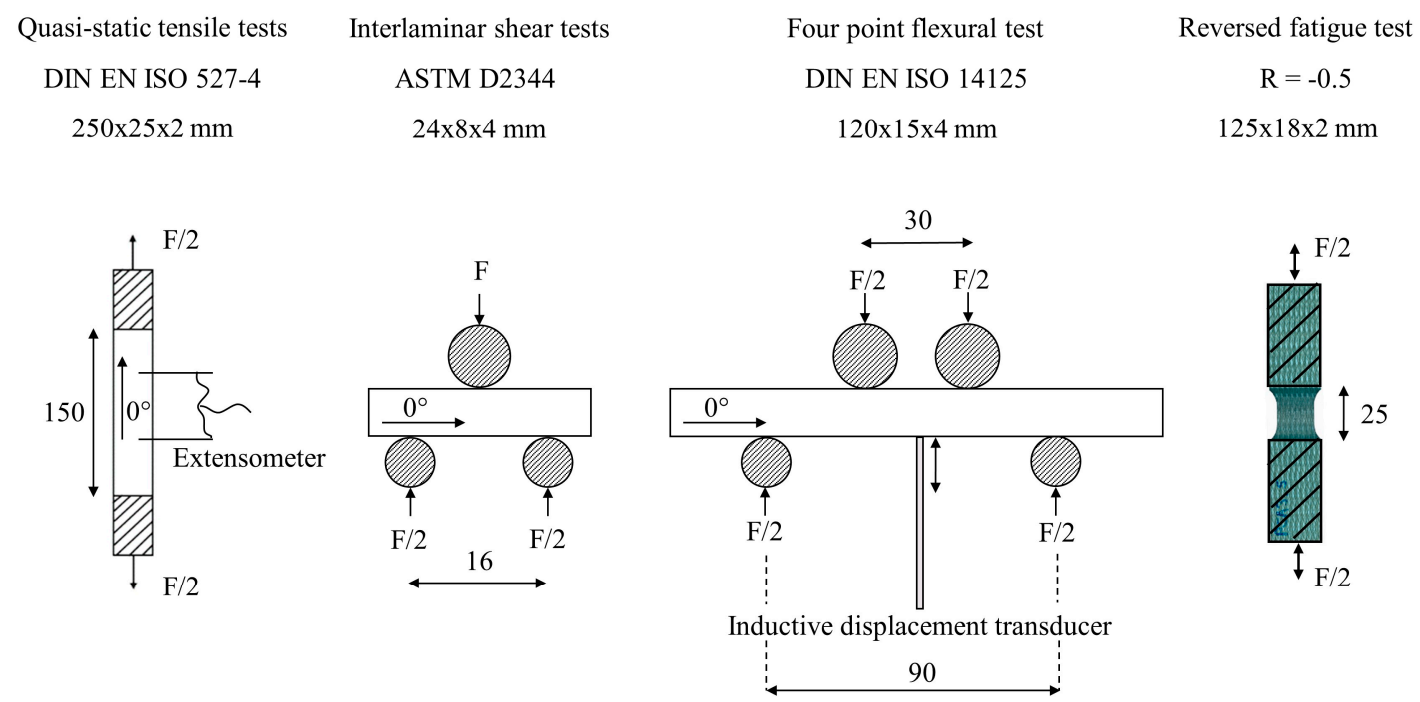

Figure A1. Schematic test configurations of the static and fatigue tests performed. Numbers are given in $\mathrm{mm}$. Further details can be found within the Section 2. 


\section{References}

1. Rocha, I.; Raijmaekers, S.; Nijssen, R.; van der Meer, F.P.; Sluys, L.J. Hygrothermal ageing behaviour of a glass/epoxy composite used in wind turbine blades. Compos. Struct. 2017, 174, 110-122. [CrossRef]

2. Miller, D.; Mandell, J. Performance of Composite Materials Subjected to Salt Water Environments. In Proceedings of the 2012 AIAA SDM Wind Energy Session, Honolulu, HI, USA, 23-26 April 2012.

3. Liao, K.; Schultheisz, C.R.; Hunston, D.L. Effects of environmental aging on the properties of pultruded GFRP. Compos. Part B Eng. 1999, 30, 485-493. [CrossRef]

4. Guzman, V.A.; Brøndsted, P. Effects of moisture on glass fiber-reinforced polymer composites. J. Compos. Mater. 2014, 49, 911-920. [CrossRef]

5. Gagani, A.I.; Mialon, E.P.; Echtermeyer, A.T. Immersed interlaminar fatigue of glass fiber epoxy composites using the I-beam method. Int. J. Fatigue 2019, 119, 302-310. [CrossRef]

6. Davies, P.; Rajapakse, Y.D. (Eds.) Durability of Composites in a Marine Environment 2; Springer International Publishing: Cham, Switzerland, 2018; pp. 225-237, ISBN 978-3-319-65145-3.

7. Bian, L.; Xiao, J.; Zeng, J.; Xing, S. Effects of seawater immersion on water absorption and mechanical properties of GFRP composites. J. Compos. Mater. 2012, 46, 3151-3162. [CrossRef]

8. Alam, P.; Robert, C.; Ó Brádaigh, C.M. Tidal turbine blade composites-A review on the effects of hygrothermal aging on the properties of CFRP. Compos. Part B Eng. 2018, 149, 248-259. [CrossRef]

9. Det Norske Veritas. DNV-OS-C501: Composite Components; Det Norske Veritas: Oslo, Norway, 2013.

10. IEC. Wind Turbines-Part 3: Design Requirements for Offshore Wind Turbines. 27.180 (IEC 61400-3). 2009. Available online: https://infostore.saiglobal.com/preview/is/en/2009/i.s.en61400-3-2009.pdf?sku=1141485 (accessed on 12 May 2019).

11. Klamer, E.; Tromp, L.; de Boer, A.; Nijssen, R. Long-term effects of wet and outdoor conditions on GFRP. IABSE Symp. Rep. 2015, 105, 1-8. [CrossRef]

12. Carra, G.; Carvelli, V. Ageing of pultruded glass fibre reinforced polymer composites exposed to combined environmental agents. Compos. Struct. 2014, 108, 1019-1026. [CrossRef]

13. Ellyin, F.; Rohrbacher, C. The Influence of Aqueous Environment, Temperature and Cyclic Loading on Glass-Fibre/Epoxy Composite Laminates. J. Reinf. Plast. Compos. 2003, 22, 615-636. [CrossRef]

14. Gautier, L.; Mortaigne, B.; Bellenger, V. Interface damage study of hydrothermally aged glass-fibre-reinforced polyester composites. Compos. Sci. Technol. 1999, 59, 2329-2337. [CrossRef]

15. Gagani, A.I.; Echtermeyer, A.T. Fluid diffusion in cracked composite laminates-Analytical, numerical and experimental study. Compos. Sci. Technol. 2018, 160, 86-96. [CrossRef]

16. Rocha, I.; Raijmaekers, S.; van der Meer, F.P.; Nijssen, R.; Fischer, H.R.; Sluys, L.J. Combined experimental/numerical investigation of directional moisture diffusion in glass/epoxy composites. Compos. Sci. Technol. 2017, 151, 16-24. [CrossRef]

17. Boisseau, A.; Davies, P.; Thiebaud, F. Sea Water Ageing of Composites for Ocean Energy Conversion Systems: Influence of Glass Fibre Type on Static Behaviour. Appl. Compos. Mater. 2012, 19, 459-473. [CrossRef]

18. Dawson, M.; Davies, P.; Harper, P.; Wilkinson, S. Composite Materials in Tidal Energy Blades. In Durability of Composites in a Marine Environment 2; Davies, P., Rajapakse, Y.D., Eds.; Springer International Publishing: Cham, Switzerland, 2018; pp. 173-194, ISBN 978-3-319-65145-3.

19. Silva, M.A.; da Fonseca, B.S.; Biscaia, H. On estimates of durability of FRP based on accelerated tests. Compos. Struct. 2014, 116, 377-387. [CrossRef]

20. Kensche, C. Fatigue of composites for wind turbines. Int. J. Fatigue 2006, 28, 1363-1374. [CrossRef]

21. Mourad, A.-H.I.; Abdel-Magid, B.M.; El-Maaddawy, T.; Grami, M.E. Effect of Seawater and Warm Environment on Glass/Epoxy and Glass/Polyurethane Composites. Appl. Compos. Mater. 2010, 17, 557-573. [CrossRef]

22. Hu, Y.; Li, X.; Lang, A.W.; Zhang, Y.; Nutt, S.R. Water immersion aging of polydicyclopentadiene resin and glass fiber composites. Polym. Degrad. Stab. 2016, 124, 35-42. [CrossRef]

23. Mandell, J.; Samborsky, D.; Miller, D. Analysis of SNL/MSU/DOE Fatigue Database Trends for Wind Turbine Blade Materials, 2010-2015; Sandia National Lab. (SNL-NM): Albuquerque, NM, USA, 2016. 
24. Jaksic, V.; Kennedy, C.R.; Grogan, D.M.; Leen, S.B.; Brádaigh, O. Influence of Composite Fatigue Properties on Marine Tidal Turbine Blade Design. In Durability of Composites in a Marine Environment 2; Davies, P., Rajapakse, Y.D., Eds.; Springer International Publishing: Cham, Switzerland, 2018; pp. 195-223, ISBN 978-3-319-65145-3.

25. Hansen, J.Z.; Brøndsted, P.; Østergaard, R. The Effects of Fibre Architecture on Fatigue Life-Time of Composite Materials. Ph.D. Dissertation, Technical University of Denmark, Kongens Lyngby, Denmark, 2013.

26. Nijssen, R. Fatigue Life Prediction and Strength Degradation of Wind Turbine Rotor Blade Composites; Delft University: Delft, The Netherlands, 2006.

27. Korkiakoski, S.; Brøndsted, P.; Sarlin, E.; Saarela, O. Influence of specimen type and reinforcement on measured tension-tension fatigue life of unidirectional GFRP laminates. Int. J. Fatigue 2016, 85, 114-129. [CrossRef]

28. Fraisse, A.; Brondsted, P. Compression fatigue of Wind Turbine Blade composites materials and damage mechanisms. In Proceedings of the 21st International Conference on Composite Materials (ICCM-21), Xi'an, China, 20-25 August 2017.

29. Li, L.; Yu, Y.; Wu, Q.; Zhan, G.; Li, S. Effect of chemical structure on the water sorption of amine-cured epoxy resins. Corros. Sci. 2009, 51, 3000-3006. [CrossRef]

30. Wang, J.; Gong, J.; Gong, Z.; Yan, X.; Wang, B.; Wu, Q.; Li, S. Effect of curing agent polarity on water absorption and free volume in epoxy resin studied by PALS. Nucl. Instrum. Methods Phys. Res. Sect. B Beam Interact. Mater. At. 2010, 268, 2355-2361. [CrossRef]

31. Ding, Y.; Liu, M.; Li, S.; Zhang, S.; Zhou, W.-F.; Wang, B. Contributions of the Side Groups to the Characteristics of Water Absorption in Cured Epoxy Resins. Macromol. Chem. Phys. 2001, 202, 2681-2685. [CrossRef]

32. DIN Deutsches Institut für Normung e.V. DIN 50905 Korrosionsuntersuchungen—Durchführung von Chemischen Korrosionsversuchen Ohne Mechanische Belastung in Flüssigkeiten im Laboratorium; DIN Deutsches Institut für Normung e.V.: Berlin, Germany, 1987.

33. Crank, J. The Mathematics of Diffusion, 2nd ed.; Oxford Univ. Press: Oxford, UK, 1975; ISBN 0198534116.

34. Shen, C.-H.; Springer, G.S. Moisture Absorption and Desorption of Composite Materials. J. Compos. Mater. 1976, 10, 2-20. [CrossRef]

35. Joliff, Y.; Rekik, W.; Belec, L.; Chailan, J.F. Study of the moisture/stress effects on glass fibre/epoxy composite and the impact of the interphase area. Compos. Struct. 2014, 108, 876-885. [CrossRef]

36. Bond, D.A. Moisture Diffusion in a Fiber-reinforced Composite: Part I-Non-Fickian Transport and the Effect of Fiber Spatial Distribution. J. Compos. Mater. 2005, 39, 2113-2141. [CrossRef]

37. Rocha, I.; van der Meer, F.P.; Raijmaekers, S.; Lahuerta, F.; Nijssen, R.; Mikkelsen, L.P.; Sluys, L.J. A combined experimental/numerical investigation on hygrothermal aging of fiber-reinforced composites. Eur. J. Mech. A/Solids 2019, 73, 407-419. [CrossRef]

38. Krauklis, A.; Echtermeyer, A. Mechanism of Yellowing: Carbonyl Formation during Hygrothermal Aging in a Common Amine Epoxy. Polymers 2018, 10, 1017. [CrossRef] [PubMed]

39. Krauklis, A.E.; Gagani, A.I.; Echtermeyer, A.T. Hygrothermal Aging of Amine Epoxy: Reversible Static and Fatigue Properties. Open Eng. 2018, 8, 447-454. [CrossRef]

40. Gamstedt, E.K.; Talreja, R. Fatigue damage mechanisms in unidirectional carbon-fibre-reinforced plastics. J. Mater. Sci. 1999, 34, 2535-2546. [CrossRef]

41. Kennedy, C.R.; Leen, S.B.; Ó Brádaigh, C.M. Immersed Fatigue Performance of Glass Fibre-Reinforced Composites for Tidal Turbine Blade Applications. J. Bio- Tribo-Corros. 2016, 2, 151. [CrossRef]

42. Castro, O.; Carraro, P.A.; Maragoni, L.; Quaresimin, M. Fatigue damage evolution in unidirectional glass/epoxy composites under a cyclic load. Polym. Test. 2019, 74, 216-224. [CrossRef]

43. Zangenberg, J.; Brøndsted, P.; Gillespie, J.W. Fatigue damage propagation in unidirectional glass fibre reinforced composites made of a non-crimp fabric. J. Compos. Mater. 2013, 48, 2711-2727. [CrossRef]

44. Gamstedt, E.; Sjögren, B. Micromechanisms in tension-compression fatigue of composite laminates containing transverse plies. Compos. Sci. Technol. 1999, 59, 167-178. [CrossRef]

45. Mandell, J.F.; Samborsky, D.D.; Miller, D.A. Effects of resin and reinforcement variations on fatigue resistance of wind turbine blades. In Advances in Wind Turbine Blade Design and Materials; Elsevier: Amsterdam, The Netherlands, 2013; pp. 210-250, ISBN 9780857094261. 
46. Nijssen, R.; Brøndsted, P. Fatigue as a design driver for composite wind turbine blades. In Advances in Wind Turbine Blade Design and Materials; Elsevier: Amsterdam, The Netherlands, 2013; pp. 175-209, ISBN 9780857094261.

47. Krauklis, A.; Gagani, A.; Vegere, K.; Kalnina, I.; Klavins, M.; Echtermeyer, A. Dissolution Kinetics of R-Glass Fibres: Influence of Water Acidity, Temperature, and Stress Corrosion. Fibers 2019, 7, 22. [CrossRef]

48. Ramirez, F.A.; Carlsson, L.A.; Acha, B.A. Evaluation of water degradation of vinylester and epoxy matrix composites by single fiber and composite tests. J. Mater. Sci. 2008, 43, 5230-5242. [CrossRef]

49. Rao, V.; Drzal, L.T. The dependence of interfacial shear strength on matrix and interphase properties. Polym. Compos. 1991, 12, 48-56. [CrossRef]

50. Krauklis, A.E.; Gagani, A.I.; Echtermeyer, A.T. Long-Term Hydrolytic Degradation of the Sizing-Rich Composite Interphase. Coatings 2019, 9, 263. [CrossRef]

51. Ochiai, S.; Hojo, M.; Schulte, K.; Fiedler, B. Nondimensional simulation of influence of toughness of interface on tensile stress-strain behavior of unidirectional microcomposite. Compos. Part A Appl. Sci. Manuf. 2001, 32, 749-761. [CrossRef]

52. Grace, L.R. Projecting long-term non-Fickian diffusion behavior in polymeric composites based on short-term data: A 5-year validation study. J. Mater. Sci. 2016, 51, 845-853. [CrossRef]

(C) 2019 by the authors. Licensee MDPI, Basel, Switzerland. This article is an open access article distributed under the terms and conditions of the Creative Commons Attribution (CC BY) license (http://creativecommons.org/licenses/by/4.0/). 